\title{
Performance assessment of circular economy for phosphorus chemical firms based on VIKOR-QUALIFLEX method
}

\author{
Wei-zhang Liang a , Guo-yan Zhao ${ }^{a,}{ }^{*}$, Chang-shou Hong ${ }^{b}$ \\ a School of Resources and Safety Engineering, Central South University, Changsha, 410083, China \\ ${ }^{\mathrm{b}}$ School of Environmental and Safety Engineering, University of South China, Hengyang, 421001, China
}

\section{A R T I C L E I N F O}

\section{Article history:}

Received 21 September 2017

Received in revised form

12 June 2018

Accepted 12 June 2018

Available online 13 June 2018

\section{Keywords:}

Circular economy (CE)

Phosphorus chemical firm (PCF)

Performance evaluation

Vlsekriterijumska optimizacija I

kompromisno resenje (VIKOR) method

Qualitative flexible (QUALIFLEX) method

Linguistic neutrosophic number (LNN)

\begin{abstract}
A B S T R A C T
Confronting the dilemma of resource shortage and environmental pollution, the idea of circular economy (CE) has attracted widespread attentions. To address these problems, several industrial companies have incorporated the $\mathrm{CE}$ in their operation or design. In this sense, the phosphorus chemical firms (PCFs) are promoting CE to achieve sustainable development goals since phosphorus is a non-renewable resource and one of the nutrient elements essential for crop growth. Thus, this paper aims to find a suitable way to assess the performance of CE for PCFs. Firstly, the evaluation index system of CE is designed according to the characteristics of CE for PCFs. Then, a new framework based on the qualitative flexible (QUALIFLEX) and Vlsekriterijumska Optimizacija I Kompromisno Resenje (VIKOR) methods is established to pick out the best enterprise. The linguistic neutrosophic number (LNN) is advised to describe decision making information with linguistic true, hesitant and false membership degree. Moreover, an entropy-based approach is used to determine the index weights, and the VIKOR method is presented to determine the concordance index. After that, all possible permutations are itemized, and the ranking result is obtained according to the general concordance index values of each permutation. Finally, an example of assessing the performance of CE for PCFs in China is given to illustrate the proposed method, and its feasibility is demonstrated. The robustness and advantage of this approach are also indicated with sensitivity and comparison analysis. The results show that the proposed VIKOR-QUALIFLEX method is reliable and stable for assessing the performance of CE for PCFs, and provides references for the construction and management of CE for PCFs.
\end{abstract}

(c) 2018 Elsevier Ltd. All rights reserved.

\section{Introduction}

Mineral resources are the material basis of human society (Ali et al., 2017; Laurence, 2011). With the development of economy, resource demand is growing dramatically (Wood et al., 2017). However, many problems occur with the traditional linear economic model (Calas, 2017; Lèbre et al., 2017). For instance, the comprehensive utilization ratio of resources is quite low, and the phenomena of environmental pollution are widespread and serious. As mineral resources are non-renewable, most mine enterprises prefer to detect a novel circular economy (CE) pattern to replace the old one (Hatayama et al., 2015).

Different from the traditional linear economic model with one-

\footnotetext{
* Corresponding author.

E-mail addresses: wzlian@csu.edu.cn (W.-z. Liang), gyzhao@csu.edu.cn (G.-y. Zhao), hongchangshou@csu.edu.cn (C.-s. Hong).
}

way flow, the CE model is a feedback process of "resources products - waste - renewable resources" (Kirchherr et al., 2017; Korhonen et al., 2018). The idea of CE was first proposed by Boulding (1966). After that, Commoner (1971) emphasized the abandon of linear production process, and advocated recycling production in modern society. Meadows et al. (1972) had the idea of the limits of the earth, and gave warnings of the development model for pursuing the continuous growth of human society. Taking into account the drawbacks of linear economic, Pearce and Turner (1990) advocated establishing a new economic growth model, called closed-loop feedback circulation model. Moreover, some international communities have actively promoted the development of CE. The World Commission on Environment and Development (WCED) (Adler et al., 2010) put forward the concept of sustainable development in the report "Our Common Future". The primary principle of sustainable development is that not only the needs of contemporary people should be met, but also the developments of offspring ought to be supported without damage. 
"Agenda 21" is one of the most important documents adopted by the United Nations Conference on Environment and Development (UNCED) (Spangenberg et al., 2002). It clarified the options and action programs that human beings should make coordination between environmental protection and sustainable development. The European Commission ((EC 2011)) established the European Resource Efficiency Platform (EREP) and developed a roadmap of resource efficiency and conservation. In China, the "Cleaner Production Promotion Law" and "Circular Economy Promotion Law" have been promulgated one after another.

On the basis of different scales, there are three levels of CE in practice, including the national level, the regional level, and the firm level (Li et al., 2010; Ma et al., 2015). Although a great many of achievements have been made in the work of $C E$ in recent years, there are still some improvements that need to be made. On the one hand, most literature focused on the evaluation of CE in first two levels, such as the assessments for countries (Hosseini and Kaneko, 2011; Shmelev and Rodríguez-Labajos, 2009), provinces (Chen et al., 2017a, b; Tsai, 2010), cities (Guo et al., 2017), and ecoindustrial parks (Pan et al., 2016; Valenzuela-Venegas et al., 2016; Zhao et al., 2017a, b). However, enterprises, which lie in fundamental positions, play an important role in the construction of CE system (Ma et al., 2015; Zhou et al., 2013). Therefore, it is necessary to study the $C E$ in enterprises. At the firm level, there are several works in the literature evaluating the performance of CE. For example, Zhou et al. (2013) employed the support vector machines to evaluate the performance of CE for iron and steel enterprise. Li and Zhao (2016) picked out a performance evaluation method for eco-industrial thermal power plants based on fuzzy GRA-VIKOR model. Azapagic (2004) established the evaluation index system of sustainable development for mining and minerals industry in detail. Yet, since the conditions of different industries are various, these approaches may not be suitable to assess the performance of CE for every chemical firm.

On the other hand, as a rare and strategic resource (Nesme and Withers, 2016), phosphorus is a chief chemical raw material of making phosphate fertilizer, phosphoric acid, yellow phosphorus, etc. (Cooper et al., 2011; Cordell and Neset, 2014). Approximately 90\% of phosphorus is applied in agriculture (Brunner, 2010). Therefore, the scarcity of phosphorus resources is directly related to food security and social stability (Cordell et al., 2011; Cordell and White, 2014). Recently, the situation of global phosphorus rock supply has become more and more grim. Several researches indicated that phosphate rock reserves would be exhausted in the next 50-100 years (Cooper et al., 2011; Cordell et al., 2011; Smit et al., 2009), and the global phosphorus scarcity is likely to be one of the greatest challenges in the 21st century (Cordell et al., 2011). In order to achieve the sustainable development of phosphorus resources, lots of phosphorus chemical firms (PCFs) are beginning to develop CE. Ma et al. (2015) constructed a phosphorus chemical optimization model under $\mathrm{CE}$, and improved the resource and economic efficiency of PCFs in Wengfu Group. Li et al. (2008a, b) proposed a backfilling method using phosphogypsum as filling material, and mitigate its environmental effect in Kailin Group. Nevertheless, so far, few experts research the performance evaluation of CE in PCFs. For these reasons, it is more urgent to find applicable methods to evaluate the performance of CE for several PCFs.

The performance evaluation of CE for PCFs, which contains various aspects including economic, technological, environmental, managerial factors, etc., is a complex system (Wu et al., 2009). Considering that many indexes exist in evaluation process, the qualitative flexible (QUALIFLEX) approach is more suitable to deal with such problems (Chen et al., 2013; Liu et al., 2016). The outranking method, QUALIFLEX, is a mature and feasible decision making method. The QUALIFLEX method supposes that there are not completely compensable relationships among indexes. It is more suitable for dealing with group decision making problems where there are interactions among decision makers (DMs), or the number of alternatives is relatively small while that of indexes is large. It has attracted many attentions and has been applied into many areas. Zhang (2016) suggested a hierarchical QUALIFLEX method on the basis of closeness index to get ranks. Wang et al. (2017a, b) combined cloud model and QUALIFLEX to assess the green suppliers. Ji et al. (2017) proposed a QUALIFLEX and Tomada de Decisão Interativa Multicritério (TODIM) approach to choose the medical treatments. Zhang (2017) selected the optimal supplier with a likelihood-based QUALIFLEX method under hesitant fuzzy environment. The key step of QUALIFLEX is to determine the general concordance index. However, in traditional QUALIFLEX, the score functions are often used to define concordance index. Maybe other suitable measures can also be regarded as concordance index to modify or extend the QUALIFLEX method.

Accordingly, the motivations and innovations of this paper are listed as follows:

(1) In reality, people prefer to make evaluations by means of linguistic phrases, such as "very good", "good", "bad", etc ( $\mathrm{Li}$ and Zhao, 2016; Zhao et al., 2017a, b). In order to fully utilize assessment values, linguistic neutrosophic number (LNN) is suggested to describe decision making information. Hence, all the membership degrees related to truth, hesitance and false can be manifested in a LNN.

(2) There are many evaluation indicators, such as phosphorus resource output, energy consumption and management level (Wu et al., 2009). In this case, it may be difficult for DMs to directly determine criteria weight values, because the index weights may be uncertain for DMs, and the aggregation process may be complex. Therefore, an entropy-based method corresponding to LNN is presented to determine the weight information. It is an objective weighting method, which can do with uncertainty and avoid the influence of subjective factors at the same time.

(3) For selecting the best enterprise with convenience and efficiency, the QUALIFLEX method is an appropriate choice. In this paper, the group utility and the individual regret are combined as concordance index to extend conventional QUALIFLEX. These two vital factors are included in the Vlsekriterijumska Optimizacija I Kompromisno Resenje (VIKOR) approach (You et al., 2015; Zhao et al., 2017a, b). The largest advantage of VIKOR method is that it considers both the maximization of group utility and the minimization of individual regret (Rostamzadeh et al., 2015). However, this method is a "choice" orientation method. That is to say, it is intended to find a compromise solution set for further choice, instead of a ranking result. By contrast, QUALIFLEX is a "rank" orientation method, so that a complete rank can be obtained. Thus, the combined method, VIKOR-QUALIFLEX, can not only take advantages of these two approaches, but also avoid the disadvantages of them.

(4) As China is a great agricultural country, the consumption of phosphorus is quite huge (Ma et al., 2015). Besides, the current situation of phosphorus resources in China is not optimistic, and the phosphorus has been regarded as a strategic mineral resource since 2016 (The State Department, 2016). Accordingly, this paper chooses China as an illustrative example to assess the performance of CE for PCFs.

The aim of this paper is to propose a new framework for assessing the performance of CE for PCFs. Firstly, the evaluation 
index system of CE for PCFs is established. After that, the evaluation model is constructed by combining VIKOR and QUALIFLEX method, which can solve this kind of complicated and ambiguous problem efficiently. Finally, the proposed decision-making framework is applied to assess the performance of CE for PCFs in China.

The reminders of this paper are arranged as follows: In Section 2 , the evaluation index system of CE for PCFs is established. Section 3 advises a study method, which combined VIKOR and QUALIFLEX. It consists of four stages: obtain assessment values; determine index weight vector; calculate concordance index and get the optimal option. An example of assessing performance of CE for PCFs in China is given in Section 4. After that, the sensitivity and comparison analysis are shown in Section 5. In the end, some related conclusions are made.

\section{Evaluation index system of CE for PCFs}

Evaluation indexes are essential for the performance assessment of CE for PCFs (Wu et al., 2009; Zhou et al., 2013). However, the standard evaluation index system has not been formed up to now. According to the rules of "3R" (reducing, reusing, recycling) and the characteristics of CE for PCFs, the evaluation index system should not only reflect the specific technical features of a circular system, but also highlight its capability in energy conservation and emission reduction. Therefore, in order to comprehensively evaluate the performance of CE for PCFs, five main criteria, namely phosphorus resource output, resources and energy consumption, waste recycling, environmental protection and management level, are chosen. The evaluation index system of CE for PCFs is shown in Fig. 1.

\subsection{Phosphorus resource output}

The development of phosphate rock is located in upstream of the industrial chain of phosphorus chemical. Advanced technology should be adopted to reduce the loss rate and the dilution rate of phosphate ore in the process of phosphate rock mining. The subcriteria of phosphorus resource output criteria are summarized as follows:

(1) Loss rate of phosphate ore $c_{1}$

This criterion indicates the percentage of the lost ore accounts for reserves. The phosphate resources cannot be fully utilized due to the loss of ore. As a result, the loss rate of phosphate ore is chosen as an indicator (Wu et al., 2009).

(2) Dilution rate of phosphate ore $c_{2}$

This criterion depicts the degree of ore grade reduced due to the incorporation of waste rock in the mining. It makes the quality of the ore lowered and increases handling costs. For this reason, the indicator of dilution rate of phosphate ore is selected (Wu et al., 2009).

\subsection{Resources and energy consumption}

Reduction is one of the basic principal of CE. Hence, it requires us to achieve production goals with less resources and energy. Thus, the resources and energy are saved during the production process. The sub-criteria of resources and energy consumption criteria are listed as follows:

(1) Resource consumption of per unit of industrial added value $c_{3}$
The phosphorus chemical industry need to consume a lot of resources, especially phosphate rock. The less the resources consumption of per unit of industrial added value, the better the development of CE. Consequently, it reflects the comprehensive utilization of resources (Wang, 2014).

(2) Comprehensive energy consumption of per unit of industrial added value $c_{4}$

Energy including coal, electricity, etc. is essential to produce phosphorus products. If the comprehensive energy consumption of per unit of industrial added value is less, it indicates that the firm do better in energy saving (Wang, 2014).

\subsection{Waste recycling}

A lot of wastes including solid waste, liquid waste, gas waste, etc. are produced in phosphorus chemical industry. As they are also resources with great value, it is worth developing and recycling. The sub-criteria of waste recycling criteria are summarized as follows:

\section{(1) Solid waste recycling rate $c_{5}$}

Considering large amount of solid waste are produced, such as tailings, waste stone, phosphogypsum, yellow phosphorus slag, etc., solid waste recycling rate is an important indicator for performance evaluation of CE (Chen et al., 2017a, b; Zhou et al., 2012). This criterion reflects the recycle capacity of solid waste in PCFs.

(2) Waste water recycling rate $c_{6}$

In consideration of plenty of water resources consumed in the production process, it is necessary to choose waste water recycling rate as an indicator (Tran et al., 2014). This criterion reflects the recycle capacity of waste water in PCFs.

(3) Exhaust cycling rate $c_{7}$

Since lots of exhaust gases are produced, it is needed to select exhaust cycling rate as an indicator (Hou et al., 2012). This criterion reflects the recycle capacity of exhaust in PCFs.

(4) Comprehensive utilization ratio of associated resources $c_{8}$

There are a number of associated resources existing in phosphate rock, and it is regrettable to handle it as a waste. Accordingly, selecting comprehensive utilization ratio of associated resources as an indicator is necessary (Li et al., 2008a, b).

\subsection{Environmental protection}

Numerous of wastes are released in some PCFs, which would lead to environmental pollution. Among them, solid waste, waste water and exhaust emissions play important roles. Simultaneously, the investment of environmental governance should be under consideration. The sub-criteria of environmental protection criteria are listed as follows:

(1) The solid wastes emissions of per unit of industrial added value $c_{9}$

These solid wastes not only take up a lot of land, but also cause serious pollution to the surrounding environment (Elloumi et al., 2017). This criterion indicates the emissions of solid wastes 


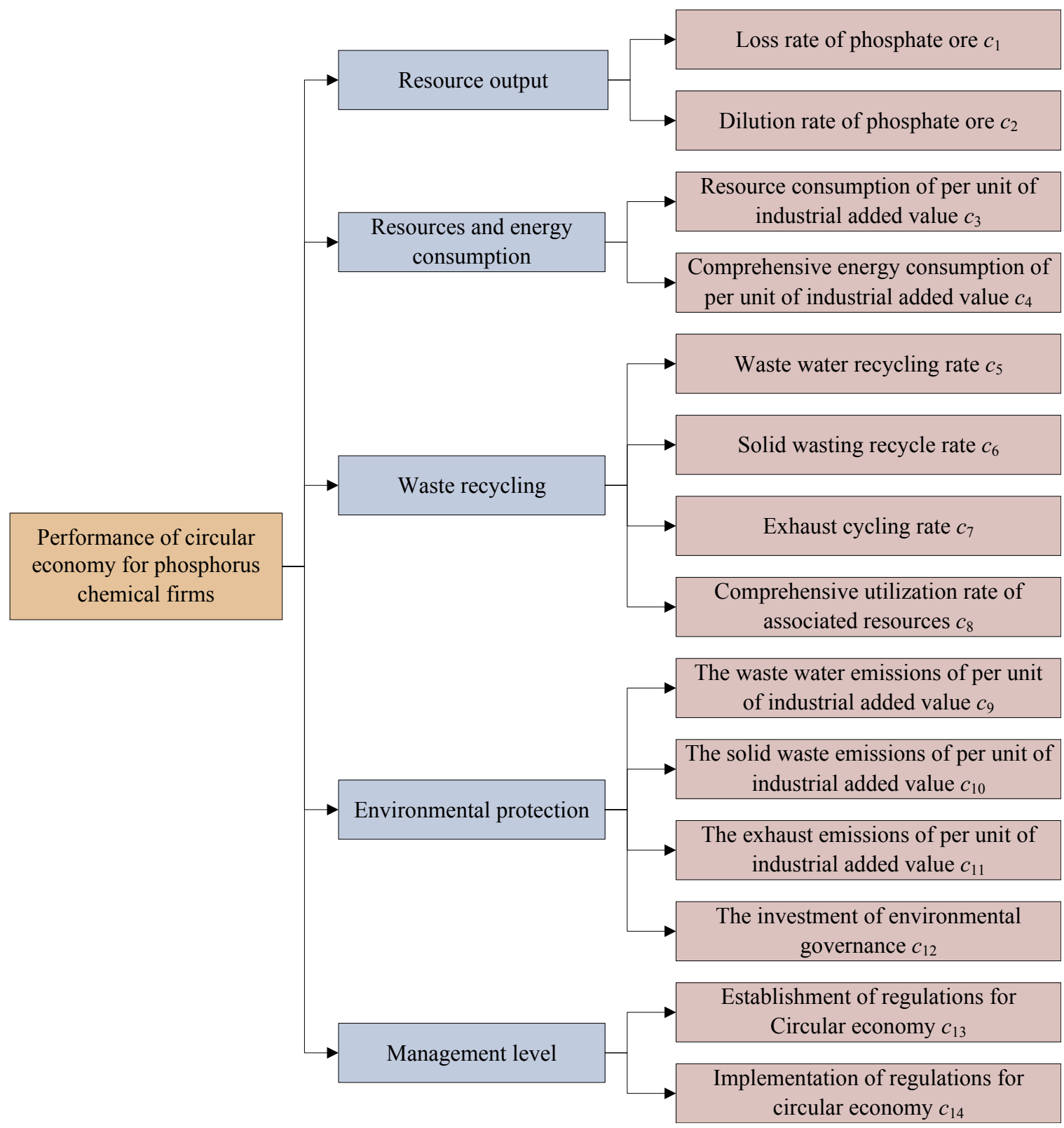

Fig. 1. The evaluation index system of CE for PCFs.

during the production for per unit of industrial added value.

(2) The waste water emissions of per unit of industrial added value $c_{10}$

The waste water contains a lot of toxic and hazardous substances, including phosphorus, fluorine, sulfur, chlorine, arsenic, alkali, uranium, etc., which are harmful to the environment (Kodera et al., 2013). This criterion reflects the emissions of waste water during the production for per unit of industrial added value.

(3) The exhaust emissions of per unit of industrial added value $c_{11}$

The exhaust during the production process of phosphorus chemical mainly consists of $\mathrm{CO}, \mathrm{SO}_{2}, \mathrm{CO}_{2}, \mathrm{HF}, \mathrm{SiF}_{4}, \mathrm{H}_{3} \mathrm{P}, \mathrm{H}_{2} \mathrm{~S}$, etc., which have a great damage on the environment (Jia, 2012). This criterion reflects the emissions of exhaust during the production for per unit of industrial added value.

(4) The investment of environmental governance $c_{12}$

Since the importance of environmental protection has been realized, large amount of excellent enterprises are committed to environmental governance. Consequently, the investment of environmental governance should be considered (Wu et al., 2009).

\subsection{Management level}

The performance of CE for PCFs should be reflected in terms of management, including establishment and implementation of regulations for $\mathrm{CE}$. The sub-criteria of management level criteria are summarized as follows: 
(1) Establishment of regulations for $\mathrm{CE} c_{13}$

In order to maintain the progress of $\mathrm{CE}$, some regulations ought to be established and improved. Therefore, the establishment of regulations for CE should be as an indicator (Wu et al., 2009).

(2) Implementation of regulations for $\mathrm{CE} c_{14}$

Once the regulations for $\mathrm{CE}$ are established, the implementation of them is necessary. Thus, the implementation of regulations for CE should be also as an indicator (Wu et al., 2009).

\section{Research approach}

A decision making method combined VIKOR and QUALIFLEX is presented in this section. The framework is depicted in Fig. 2. More details of each stage can be seen in subsections 3.1-3.4, respectively. (In order to facilitate readers to better understand, Table 9 in Appendix is added to explain some nomenclatures.)

\subsection{Stage 1: obtaining evaluation information}

With respect to a group assessment problem, $s$ DMs $\left\{g_{1}, g_{2}, \ldots, g_{s}\right\}$ try to make evaluation of $m$ options $\left\{z_{1}, z_{2}, \ldots, z_{m}\right\}$, and then pick out the optimal one. In the process of evaluation, people may be accustomed to using linguistic phrases, like "very good" (Luo et al., 2017). For convenience, these phrases can be contained in a linguistic term set (Xu, 2005). Besides, the linguistic term set can be expressed as $p=\left\{p_{b} \mid b=0,1, \ldots, 2 v\right\}$, such as: $P=$ $\left\{p_{0}=\right.$ very bad, $p_{1}=$ bad, $p_{2}=$ slightly bad, $p_{3}=$ medium, $p_{4}=$ slightly good, $p_{5}=$ good, $p_{6}=$ very good $\}$. After Xu (2005) defined the operations and comparison methods related to linguistic variables, many linguistic extensions are developed (Khishtandar et al., 2017; Liao et al., 2017; Wang et al., 2017a, b).

The evaluation information is obtained with the following steps:

Step 1: Assessing alternatives with linguistic neutrosophic numbers (LNNs).

Lately, a new extension, called LNNs, is put forward by Fang and Ye (2017). A linguistic neutrosophic number (LNN) can be denoted as $B=\left(b_{T}, b_{I}, b_{F}\right)$, where $b_{T}, b_{I}$ and $b_{F}$ are three independent linguistic phrases to express the linguistic truth-membership degree $b_{T}$, linguistic indeterminacy-membership degree $b_{I}$ and linguistic falsity-membership degree $b_{F}$, respectively. For example, the descriptions of three membership degrees with linguistic phrases "bad", "good" and "very good" can be replaced by. $B=\left(p_{1}, p_{5}, p_{6}\right)$.

Suppose $B_{1}=\left(b_{T_{1}}, b_{I_{1}}, b_{F_{1}}\right)$ and $B_{2}=\left(b_{T_{2}}, b_{I_{2}}, b_{F_{2}}\right)$ are two LNNs, then the operational rules are

$$
B_{1} \oplus B_{2}=\left(b_{T_{1}}, b_{I_{1}}, b_{F_{1}}\right) \oplus\left(b_{T_{2}}, b_{I_{2}}, b_{F_{2}}\right)=\left(b_{T_{1}+T_{2}-\frac{T_{1} T_{2}}{2 v}}, b_{\frac{I_{1} I_{2}}{2 v}}, b_{\frac{F_{1} F_{2}}{2 v}}\right) ;
$$

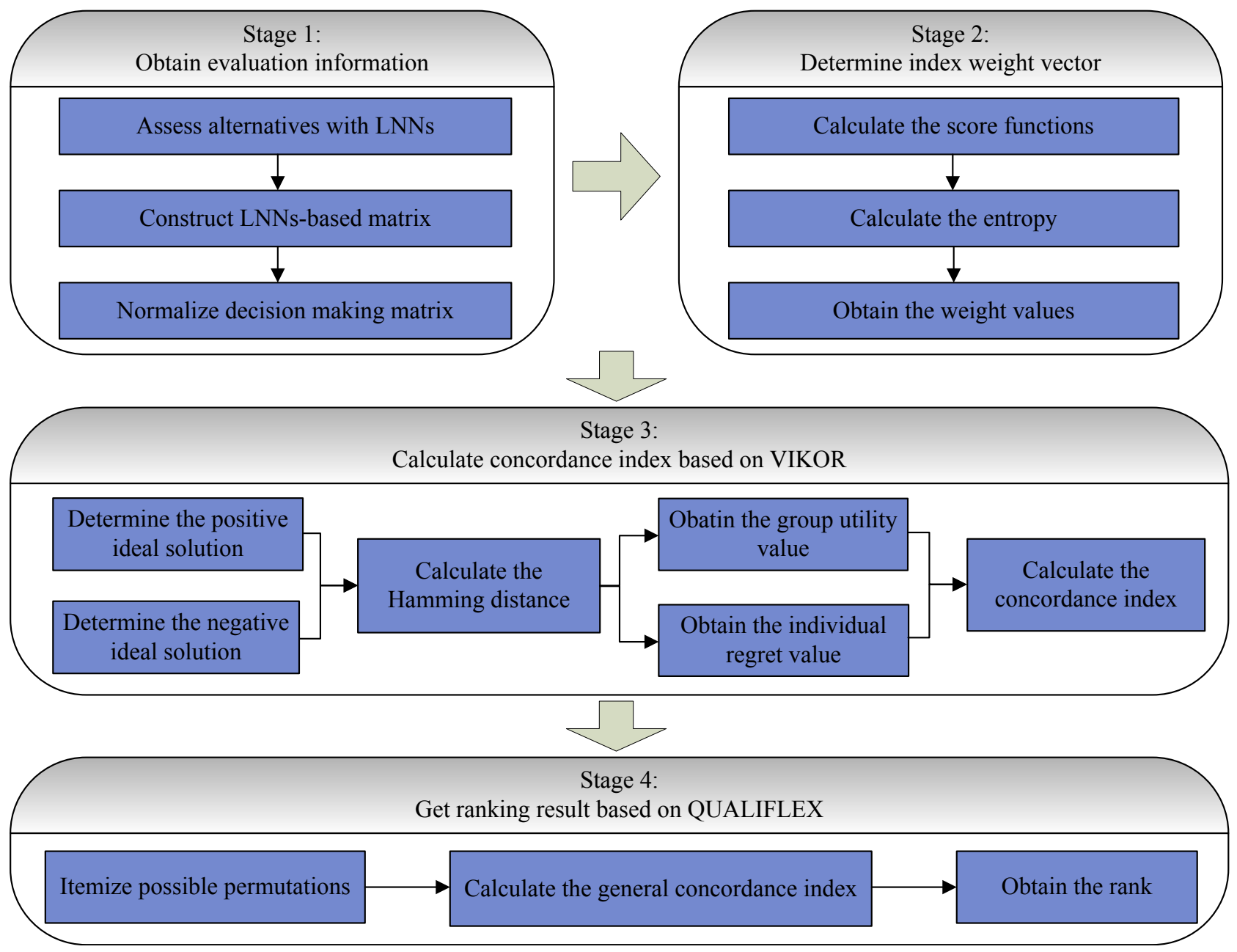

Fig. 2. The framework of the VIKOR-QUALIFLEX method. 


$$
\begin{aligned}
B_{1} \otimes B_{2} & =\left(b_{T_{1}}, b_{I_{1}}, b_{F_{1}}\right) \oplus\left(b_{T_{2}}, b_{I_{2}}, b_{F_{2}}\right) \\
& =\left(b_{\frac{T_{1} T_{2}}{2 v}}, b_{I_{1}+I_{2}-\frac{I_{1} I_{2}}{2 v}}, b_{F_{1}+F_{2}-\frac{F_{1} F_{2}}{2 v}}\right) ;
\end{aligned}
$$

$$
\begin{aligned}
\gamma B_{1} & =\gamma\left(b_{T_{1}}, b_{I_{1}}, b_{F_{1}}\right) \\
& =\left(b_{2 v-2 v\left(1-\frac{T_{1}}{2 v}\right)^{\gamma}}, b_{2 v\left(\frac{I_{1}}{2 v}\right)^{\gamma}}, b_{2 v\left(\frac{F_{1}}{2 v}\right)^{\gamma}}\right) \quad(\gamma>0) ;
\end{aligned}
$$

$$
\begin{aligned}
& B_{1}^{\gamma}=\left(b_{T_{1}}, b_{I_{1}}, b_{F_{1}}\right)^{\gamma}
\end{aligned}
$$

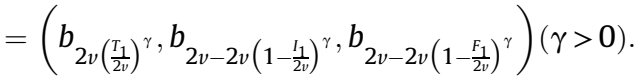

LNNs have a good feature of retaining original information as much as possible (Liang et al., 2018). Hence, the total evaluation information of all professionals under $n$ indexes $\left\{c_{1}, c_{2}, \ldots, c_{n}\right\}$ is described by means of LNNs in this study.

Step 2: Constructing LNNs-based matrix.

Then, all of the evaluation information with LNNs is contained in a general decision making matrix as follows:

$$
\begin{aligned}
H & =\left(B_{i j}\right)_{n \times m}=\left[\begin{array}{ccc}
B_{11} & \cdots & B_{1 m} \\
B_{21} & \cdots & B_{2 m} \\
\vdots & \cdots & \vdots \\
B_{n m} & \cdots & B_{n m}
\end{array}\right] \\
& =\left[\begin{array}{ccc}
\left(b_{T_{11}}, b_{I_{11}}, b_{F_{11}}\right) & \cdots & \left(b_{T_{1 m}}, b_{I_{1 m}}, b_{F_{1 m}}\right) \\
\left(b_{T_{21}}, b_{I_{21}}, b_{F_{21}}\right) & \cdots & \left(b_{T_{2 m}}, b_{I_{2 m}}, b_{F_{2 m}}\right) \\
\vdots & \cdots & \vdots \\
\left(b_{T_{n 1}}, b_{I_{n 1}}, b_{F_{n 1}}\right) & \cdots & \left(b_{T_{n m}}, b_{I_{n m}}, b_{F_{n m}}\right)
\end{array}\right] .
\end{aligned}
$$

Step 3: Normalizing decision making matrix.

On account of several cost indexes, some conversions need to be used by following formula (Liang et al., 2017):

$\left.\begin{array}{l}b_{T_{i j}}^{c}=b_{T_{2 v-i j}} \\ b_{I_{i j}}^{c}=b_{I_{2 v-i j}} \\ b_{F_{i j}}^{c}=b_{F_{2 v-i j}}\end{array}\right\}$.

Thus, the normalized decision making matrix is denoted as. $H^{c}=\left(B_{i j}^{c}\right)_{n \times m}=\left(b_{T_{i j}}^{c}, b_{I_{i j}}^{c}, b_{F_{i j}}^{c}\right)_{n \times m}$.

\subsection{Stage 2: determining index weight vector}

To make assessment of an option, many indexes may be taken into account. In most cases, the importance or weight of each index is not equal. Therefore, an algorithm to determine index weight vector on the basis of entropy is proposed.

Entropy theory presented by Shannon is used to measure the amount of information (Shannon, 1948). If the entropy of an evaluation index is smaller, it indicates that this index carries more information, and has a greater impact on final results. Entropybased method is an objective method through calculating index weight, which can avoid the influence of subjective factors (Zhao et al., 2017a, b). The calculation steps are as follows:

\section{Step 1: Calculating the score functions.}

Calculate the score function $K\left(B_{i j}\right)$ (Fang and Ye, 2017) ( $i=1,2$, $\ldots, n, j=1,2, \ldots, m)$ of each LNN in the comprehensive decision matrix with the following formula:

$K\left(B_{i j}\right)=\left(4 v+T_{i j}-I_{i j}-F_{i j}\right) /(6 v)$,

Step 2: Calculating the entropy.

Calculate the entropy $Y_{i}(i=1,2, \ldots, n)$ of each row with the following formulas:

$$
\begin{aligned}
& Y_{i}=-\frac{1}{\ln m} \sum_{j=1}^{m} K_{i j} \ln K_{i j}, \\
& K_{i j}=K\left(B_{i j}\right) / \sum_{j=1}^{m} K\left(B_{i j}\right) .
\end{aligned}
$$

Step 3: Obtaining the weight values.

Calculate the weight values of each index $c_{i}(i=1,2, \ldots, n)$ with the following formula:

$\omega_{i}=\left(1-Y_{i}\right) / \sum_{i=1}^{n}\left(1-Y_{i}\right)$.

\subsection{Stage 3: calculating concordance index based on VIKOR}

Opricovic and Tzeng (2004) firstly presented the VIKOR method. The basic idea of VIKOR method is to pursue the maximization of group benefit and the minimization of individual regret. The rank is obtained through identifying the ideal solutions, and then calculating the group utility value, the individual regret value and the compromise solution. It is applicable for DMs who prefer to maximize profit.

The algorithm of calculating concordance index is shown as follows:

Step 1: Determining the positive and negative ideal solutions.

Determine the positive ideal solution $B_{i}^{+}=\left(b_{T_{i}^{+}}, b_{I_{i}^{+}}, b_{F_{i}^{+}}\right)$and negative ideal solution $B_{i}^{-}=\left(b_{T_{i}^{-}}, b_{I_{i}^{-}}, b_{F_{i}^{-}}\right)$of each row.

The size of two LNNs is determined by the score function $K\left(B_{i j}\right)$ (Equation (2)) and the accuracy function $F\left(B_{i j}\right.$ ) (Equation (6)) (Fang and Ye, 2017). Suppose $B_{1}=\left(b_{T_{1}}, b_{I_{1}}, b_{F_{1}}\right)$ and $B_{2}=\left(b_{T_{2}}, b_{I_{2}}, b_{F_{2}}\right)$ are two random LNNs, if $K\left(B_{1}\right)<K\left(B_{2}\right)$, then $B_{1}<B_{2}$; if $K\left(B_{1}\right)=K\left(B_{2}\right)$ and $F\left(B_{1}\right)<F\left(B_{2}\right)$, then $B_{1}<B_{2}$; if $K\left(B_{1}\right)=K\left(B_{2}\right)$ and $F\left(B_{1}\right)=F\left(B_{2}\right)$, then $B_{1} \sim B_{2}$.

$F\left(B_{i j}\right)=\left(T_{i j}-F_{i j}\right) /(2 v)$,

\section{Step 2: Calculating the Hamming distance.}

Calculate the Hamming distance between each LNN (Liang et al., 2017) and the corresponding positive ideal solution in same line with the following formula:

$d\left(B_{i j}, B_{i}^{+}\right)=\frac{1}{6 v}\left(\left|T_{i j}-T_{i}^{+}\right|+\left|I_{i j}-I_{i}^{+}\right|+\left|F_{i j}-F_{i}^{+}\right|\right)$

Step 3: Obtaining the group utility and individual regret values.

Calculate the group utility value $U_{j}$ and individual regret value $R_{j}(j=1,2, \ldots, m)$ of each option with the following formulas:

$U_{j}=\sum_{i=1}^{n} \frac{\omega_{i} d\left(B_{i}^{+}, B_{i j}\right)}{d\left(B_{i}^{+}, B_{i}^{-}\right)}$,

$R_{j}=\max _{i}\left\{\frac{\omega_{i} d\left(B_{i}^{+}, B_{i j}\right)}{d\left(B_{i}^{+}, B_{i}^{-}\right)}\right\}$,

Step 4: Calculating the concordance index.

Calculate the concordance index of option $z_{j}(j=1,2, \ldots, m)$ over option $z_{k}(k=1,2, \ldots, m)$ with the following formula: 
$C C_{j k}=\lambda \frac{U_{k}-U_{j}}{U_{j}^{+}-U_{j}^{-}}+(1-\lambda) \frac{R_{k}-R_{j}}{R_{j}^{+}-R_{j}^{-}}$,

where $U_{j}^{+}=\max _{j}\left(U_{j}\right), U_{j}^{-}=\min _{j}\left(U_{j}\right), R_{j}^{+}=\max _{j}\left(R_{j}\right), R_{j}^{-}=\min _{j}\left(R_{j}\right)$, and $\lambda \in[0,1]$ is a decision making mechanism coefficient.

\subsection{Stage4: Getting ranking result based on QUALIFLEX}

Utilizing the concordance index, a ranking order can be obtained based on QUALIFLEX. It is especially applicable and effective when the number of indexes distinctly exceeds the number of alternatives in a decision making problem.

The detailed steps are displayed as follows (Ji et al., 2017):

\section{Step 1: Itemizing possible permutations.}

Itemize $m$ ! possible permutations, denoted as $r_{p}=\left(\ldots, z_{j}, \ldots, z_{k}\right.$, $\ldots)$, where option $z_{k}$ is no better than option $z_{j}$, and $p=1,2, \ldots, m !$.

Step 2: Calculating the general concordance index.

Calculate the general concordance index in each permutation with the following formula:

$C I_{p}=\sum_{j=1}^{m !-1} \sum_{k=j+1}^{m !} C I_{j k}(p=1,2, \ldots, m !)$.

\section{Step 3: Obtaining the rank.}

Obtain the rank in line with the values of $C I_{p}(p=1,2, \ldots, m !)$. The bigger the values of $C I_{p}$, the better the permutation. $r_{p}$.

\section{Case study}

In this section, the proposed VIKOR-QUALIFLEX method is applied to assess the performance of CE for PCFs in China. First, the current situation of China's phosphorus chemical industry is analyzed. Then, an illustrative example is presented to demonstrate the applicability of this approach.

\subsection{The current situation of China's phosphorus chemical industry}

\section{(1) Characteristic of phosphate rock}

The development of phosphate rock is the basis of phosphorus chemical industry. According to statistics from the United States Geologic Survey (USGS) in 2013 (Van Kauwenbergh et al., 2013), the phosphate rock mainly distributes over four countries, namely Morocco and Western Sahara, China, Algeria and Syria, which is up to $87 \%$ of global reserves. After Morocco, China has the secondhighest reserves of phosphate rock all over the world.

The phosphate rock reserves from 2006 to 2015 in China are demonstrated in Fig. 3 (NBSPRC, 2016). Even though the large consumption of phosphorus resources lead to its decrease with time, phosphate rock reserves is rising slightly with numerous new phosphorus orebody explored. Fig. 3 also describes the per capita availability of phosphate rock. Since China has a large population, the per capita availability of phosphate rock is still low.

The distribution of phosphate rock is unbalanced (see Fig. 4), and mainly occurs in Guizhou, Hubei, Sichuan and Yunnan province (NBSPRC, 2016). Specifically, they are concentrated in Wengfu and Kaiyang in Guizhou province, Yichang, Huji and Baokang in Hubei province, Jinhe - Qingping and Mabian in Sichuan province, and Dianchi in Yunnan province (Jia, 2012).

In addition, lots of orebody are inclined and thin or medium heavy. These deposit conditions have greatly increased the difficulty of mining. It is likely to bring a lot of problems, such as high dilution rate, great loss rate, expensive production costs. Therefore, the situation of phosphorus resources in China is not optimistic.

\section{(2) Resource recovery of phosphate rock}

Phosphate rock can be processed into many products. Most of phosphate rock in China is used to produce phosphate fertilizer (Jia, 2012). However, a large amount of phosphorus has not been utilized adequately as well. Besides, the phosphorus over standard may have great negative effect on the ecological environment, such as water eutrophication.

Wastes produced from mining and processing of phosphate rock, including waste stone, phosphogypsum, yellow phosphorus slag, waste water, exhaust gas, etc., are also useful resource. However, owing to the factors of technique or cost, they are not fully utilized in China. On the contrary, some of them are discharged directly, which bring a great threat to the ecological environment and public safety. In addition, some associated resources, such as iodine, fluorine, magnesium, molybdenum, etc., are also included in phosphate rock. At present, most of PCFs in China mainly focus on the development of phosphorus, the comprehensive utilization ratio of associated resources is still low, which leads to a great waste.

In order to improve the resource recovery rate of phosphate rock, it is necessary to develop a CE for PCFs in China. The utilization model of phosphorus resources has been greatly changed, as shown in Fig. 5 (Li and Jia, 2006). Some measures have been conducted, such as the improvements of production technology, comprehensive utilization of waste, recycling of resources, management of the environment, etc. On account of the differences in the development pattern of CE for different enterprises, it is needed to establish a CE evaluation system for PCFs in China.

\subsection{An illustrative example}

In this subsection, the performance of CE for four PCFs (denoted as $z_{1}, z_{2}, z_{3}$ and $z_{4}$ ) in China is assessed by using proposed VIKORQUALIFLEX method. These four PCFs demonstrate a favorable performance of CE. The developmental pattern of them can enhance the resource recovery rate of phosphate rock and reduce environmental problems. Accordingly, the mutual benefits of economy and environment can be obtained, which indicate typical characteristics of CE for PCFs. The specific calculation steps to select the best one from these four enterprises are presented below.

In stage 1: A group of professionals were invited to evaluate the performance of CE for four companies with LNN. After in-depth investigations and heated discussions, the initial assessment matrix was indicated in Table 10 (See Appendix). Then, the normalized assessment matrix was calculated by Equation (1), which was listed in Table 1.

In stage 2: At first, the values of score function $K\left(B_{i j}\right)$ were calculated based on Equation (2), as depicted in Table 11 (See Appendix). Then, the entropy values $Y_{i}$ and the weight values $w_{i}$ of each index $c_{i}$ were calculated by using Equations (3)-(5), as shown in Table 2.

In stage 3: Firstly, the positive ideal solution $B_{i}^{+}=\left(b_{T_{i}}^{+}, b_{I_{i}}^{+}, b_{F_{i}}^{+}\right)$ and the negative ideal solution $B_{i}^{-}=\left(b_{T_{i}}^{-}, b_{I_{i}}^{-}, b_{F_{i}}^{-}\right)$of each row were determined, as shown in Table 12 (See Appendix). Then, the distance between each LNN and the corresponding positive ideal solution in same row were obtained using Equation (7), as listed in Table 13 (See Appendix). After that, the group utility value $U_{j}$ and individual regret value $R_{j}$ were calculated on the basis of Equations 


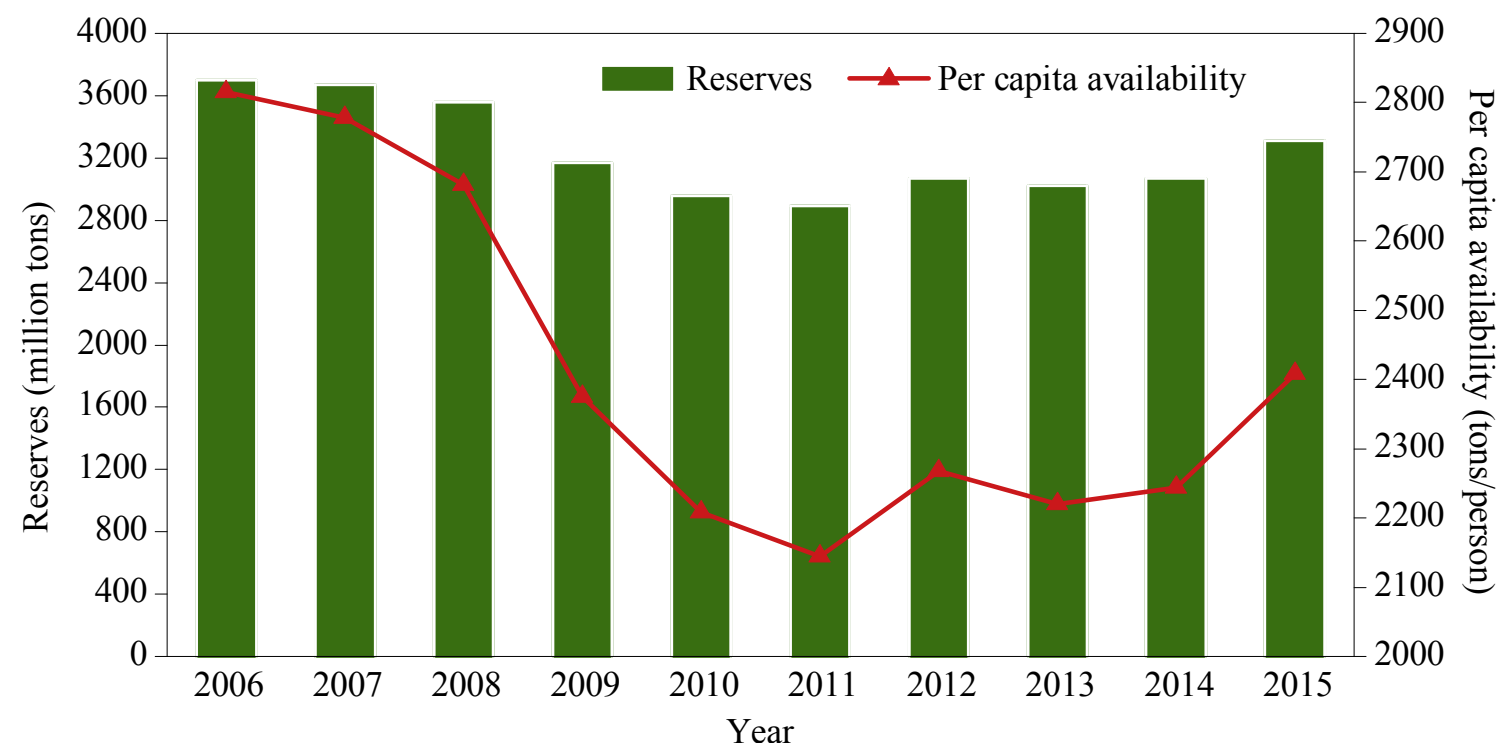

Fig. 3. The reserves and per capita availability of phosphate rock (Data sources (NBSPRC, 2016)).

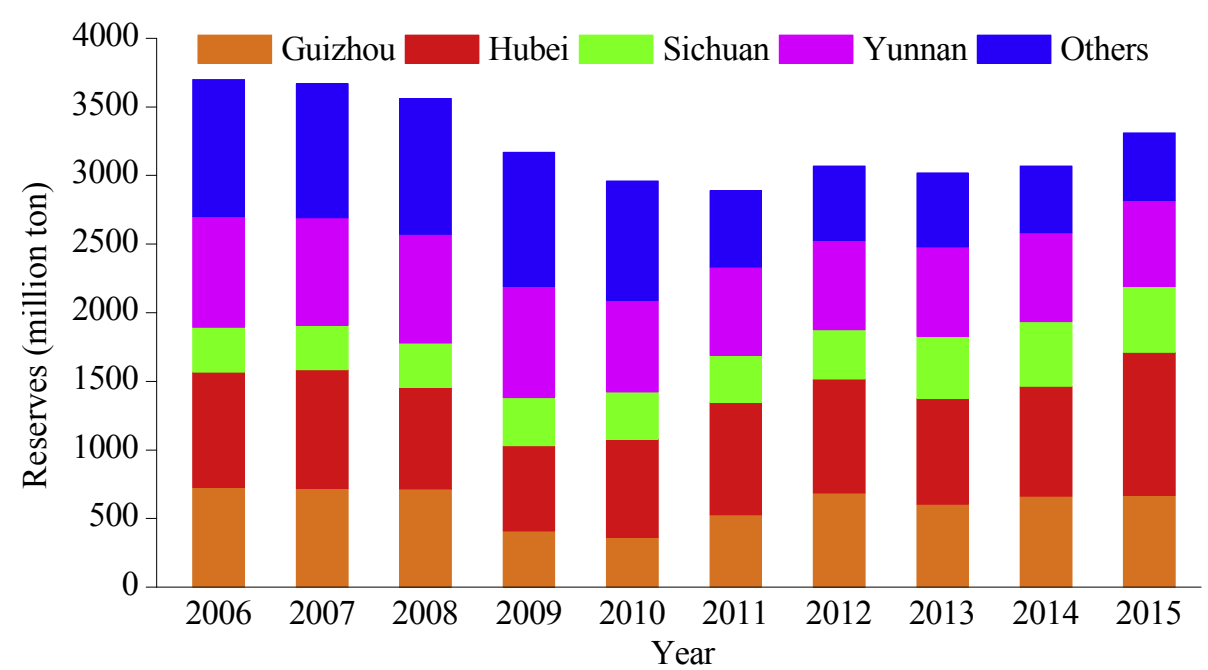

Fig. 4. Distribution of phosphate rock reserves in China (Data sources (NBSPRC, 2016).

(8) and (9), as presented in Table 3. Finally, suppose $\lambda=0.5$, the concordance index was derived with Equation (10), as shown in Table 4.

In stage 4: All 24 possible permutations were itemized: $r_{1}=\left(z_{1}, z_{2}, z_{3}, z_{4}\right), \quad r_{2}=\left(z_{1}, z_{2}, z_{4}, z_{3}\right), \quad r_{3}=\left(z_{1}, z_{3}, z_{2}, z_{4}\right)$, $r_{4}=\left(z_{1}, z_{3}, z_{4}, z_{2}\right), \quad r_{5}=\left(z_{1}, z_{4}, z_{2}, z_{3}\right), \quad r_{6}=\left(z_{1}, z_{4}, z_{3}, z_{2}\right)$, $r_{7}=\left(z_{2}, z_{1}, z_{3}, z_{4}\right), r_{8}=\left(z_{2}, z_{1}, z_{4}, z_{3}\right), r_{9}=\left(z_{2}, z_{3}, z_{1}, z_{4}\right), r_{10}=\left(z_{2}\right.$, $\left.z_{3}, z_{4}, z_{1}\right), \quad r_{11}=\left(z_{2}, z_{4}, z_{1}, z_{3}\right), \quad r_{12}=\left(z_{2}, z_{4}, z_{3}, z_{1}\right)$, $r_{13}=\left(z_{3}, z_{1}, z_{2}, z_{4}\right), \quad r_{14}=\left(z_{3}, z_{1}, z_{4}, z_{2}\right), \quad r_{15}=\left(z_{3}, z_{2}, z_{1}, z_{4}\right)$, $r_{16}=\left(z_{3}, z_{2}, z_{4}, z_{1}\right), \quad r_{17}=\left(z_{3}, z_{4}, z_{1}, z_{2}\right), \quad r_{18}=\left(z_{3}, z_{4}, z_{2}, z_{1}\right)$, $r_{19}=\left(z_{4}, z_{1}, z_{2}, z_{3}\right), \quad r_{20}=\left(z_{4}, z_{1}, z_{3}, z_{2}\right), \quad r_{21}=\left(z_{4}, z_{2}, z_{1}, z_{3}\right)$, $r_{22}=\left(z_{4}, z_{2}, z_{3}, z_{1}\right), r_{23}=\left(z_{4}, z_{3}, z_{1}, z_{2}\right), r_{24}=\left(z_{4}, z_{3}, z_{2}, z_{1}\right)$. Then, the general concordance index of each permutation was calculated with Equation (11), as shown in Table 5. Since $C I_{8}=3.6316$ is the largest value, then the rank is $z_{2}>z_{1}>z_{4}>z_{3}$, and the optimal option is. $z_{2}$.

\section{Sensitivity and comparison analysis}

In this section, sensitivity and comparison analysis are provided to reveal the robustness, effectiveness and highlights of the presented approach.

\subsection{Sensitivity analysis}

In stage 4 of the research approach, a parameter $\lambda$ is introduced to coordinate the group utility and the individual regret (see Equation (10)). Generally, a consensus decision making mechanism is adapted, and $\lambda=0.5$ is made from an equilibrium point of view. However, the value of $\lambda$ may be various for different experts or groups. When DMs highlight the maximization of group utility, the value of this parameter will become larger, and $0.5 \leq \lambda \leq 1$. On the contrary, a small $\lambda$ will be given when DMs has emphasize on the minimization of individual regret, and $0 \leq \lambda \leq 0.5$. The value of $\lambda$ affects the value of concordance index, and the concordance index has a decisive role in obtaining rank. Consequently, it is necessary to analyze the effects of this parameter $\lambda$ on ranking orders. Fig. 6 describes the results of the proposed method using different $\lambda$ values when $0 \leq \lambda \leq 0.5$. Fig. 7 illustrates the results of the proposed method with different $\lambda$ values when $0.5 \leq \lambda \leq 1$. 


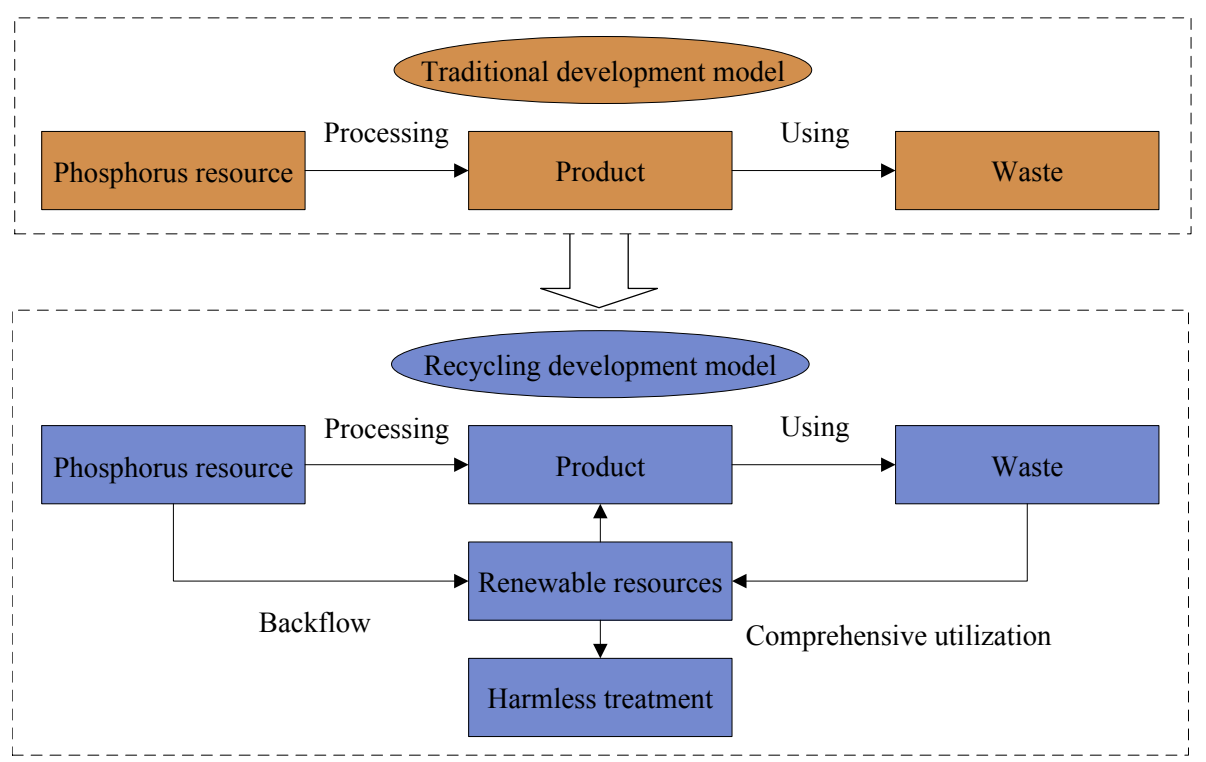

Fig. 5. The development model of phosphorus resources.

Table 1

Normalized assessment matrix. $H^{c}$

\begin{tabular}{lllll}
\hline$H^{c}$ & $z_{1}$ & $z_{2}$ & $z_{3}$ & $z_{4}$ \\
\hline$c_{1}$ & $\left(p_{4}, p_{3}, p_{2}\right)$ & $\left(p_{5}, p_{4}, p_{2}\right)$ & $\left(p_{5}, p_{1}, p_{1}\right)$ & $\left(p_{4}, p_{2}, p_{4}\right)$ \\
$c_{2}$ & $\left(p_{3}, p_{2}, p_{3}\right)$ & $\left(p_{5}, p_{1}, p_{1}\right)$ & $\left(p_{4}, p_{1}, p_{3}\right)$ & $\left(p_{5}, p_{3}, p_{1}\right)$ \\
$c_{3}$ & $\left(p_{2}, p_{3}, p_{1}\right)$ & $\left(p_{4}, p_{3}, p_{1}\right)$ & $\left(p_{3}, p_{3}, p_{2}\right)$ & $\left(p_{5}, p_{4}, p_{3}\right)$ \\
$c_{4}$ & $\left(p_{4}, p_{1}, p_{1}\right)$ & $\left(p_{4}, p_{2}, p_{1}\right)$ & $\left(p_{5}, p_{2}, p_{4}\right)$ & $\left(p_{3}, p_{1}, p_{2}\right)$ \\
$c_{5}$ & $\left(p_{5}, p_{3}, p_{2}\right)$ & $\left(p_{4}, p_{3}, p_{4}\right)$ & $\left(p_{3}, p_{5}, p_{2}\right)$ & $\left(p_{2}, p_{4}, p_{1}\right)$ \\
$c_{6}$ & $\left(p_{5}, p_{1}, p_{4}\right)$ & $\left(p_{3}, p_{2}, p_{4}\right)$ & $\left(p_{4}, p_{4}, p_{3}\right)$ & $\left(p_{4}, p_{1}, p_{1}\right)$ \\
$c_{7}$ & $\left(p_{3}, p_{1}, p_{2}\right)$ & $\left(p_{5}, p_{1}, p_{2}\right)$ & $\left(p_{5}, p_{3}, p_{5}\right)$ & $\left(p_{3}, p_{3}, p_{2}\right)$ \\
$c_{8}$ & $\left(p_{3}, p_{1}, p_{3}\right)$ & $\left(p_{5}, p_{2}, p_{1}\right)$ & $\left(p_{5}, p_{3}, p_{2}\right)$ & $\left(p_{4}, p_{2}, p_{4}\right)$ \\
$c_{9}$ & $\left(p_{4}, p_{2}, p_{3}\right)$ & $\left(p_{4}, p_{2}, p_{4}\right)$ & $\left(p_{4}, p_{3}, p_{5}\right)$ & $\left(p_{4}, p_{3}, p_{3}\right)$ \\
$c_{10}$ & $\left(p_{3}, p_{1}, p_{2}\right)$ & $\left(p_{4}, p_{3}, p_{1}\right)$ & $\left(p_{5}, p_{1}, p_{1}\right)$ & $\left(p_{5}, p_{4}, p_{4}\right)$ \\
$c_{11}$ & $\left(p_{5}, p_{1}, p_{2}\right)$ & $\left(p_{4}, p_{2}, p_{2}\right)$ & $\left(p_{5}, p_{1}, p_{2}\right)$ & $\left(p_{3}, p_{2}, p_{4}\right)$ \\
$c_{12}$ & $\left(p_{4}, p_{2}, p_{5}\right)$ & $\left(p_{5}, p_{1}, p_{1}\right)$ & $\left(p_{3}, p_{4}, p_{4}\right)$ & $\left(p_{2}, p_{4}, p_{1}\right)$ \\
$c_{13}$ & $\left(p_{3}, p_{2}, p_{1}\right)$ & $\left(p_{4}, p_{3}, p_{2}\right)$ & $\left(p_{5}, p_{2}, p_{1}\right)$ & $\left(p_{5}, p_{1}, p_{1}\right)$ \\
$c_{14}$ & $\left(p_{4}, p_{3}, p_{1}\right)$ & $\left(p_{2}, p_{2}, p_{1}\right)$ & $\left(p_{4}, p_{1}, p_{3}\right)$ & $\left(p_{4}, p_{3}, p_{2}\right)$ \\
\hline
\end{tabular}

Table 2

The entropy values $Y_{i}$ and weight values. $\omega_{i}$

\begin{tabular}{llllllll}
\hline & $c_{1}$ & $c_{2}$ & $c_{3}$ & $c_{4}$ & $c_{5}$ & $c_{6}$ & $c_{7}$ \\
\hline$Y_{i}$ & 1.2503 & 1.2523 & 1.2589 & 1.2582 & 1.2509 & 1.2451 & 1.2487 \\
$\omega_{i}$ & 0.0713 & 0.0719 & 0.0737 & 0.0735 & 0.0715 & 0.0698 & 0.0708 \\
\hline & $c_{8}$ & $c_{9}$ & $c_{10}$ & $c_{11}$ & $c_{12}$ & $c_{13}$ & $c_{14}$ \\
\hline$Y_{i}$ & 1.2547 & 1.2560 & 1.2475 & 1.2485 & 1.2234 & 1.2551 & 1.2610 \\
$\omega_{i}$ & 0.0726 & 0.0729 & 0.0705 & 0.0708 & 0.0636 & 0.0727 & 0.0743 \\
\hline
\end{tabular}

Table 3

Group utility $U_{j}$ and individual regret. $R_{j}$

\begin{tabular}{lllll}
\hline & $z_{1}$ & $z_{2}$ & $z_{3}$ & $z_{4}$ \\
\hline$U_{j}$ & 0.5293 & 0.4557 & 0.7884 & 0.7776 \\
$R_{j}$ & 0.0908 & 0.0743 & 0.1838 & 0.1474 \\
\hline
\end{tabular}

As shown in Figs. 6 and 7, the ultimate ranking results are consistent. The trends of the general concordance index for each permutation in both figures are also similar. The optimal permutation is always $r_{8}$ for different $\lambda$ values, and the rank is $z_{2}>z_{1}>z_{4}>z_{3}$ in two figures. It means that although DMs considered different degrees of group utility and individual regret, they all regarded $r_{8}$ as the best result, and $z_{2}$ as the optimal option.
Table 4

The concordance index. $C I_{j k}$

\begin{tabular}{lllll}
\hline$C I_{j k}$ & $z_{1}$ & $z_{2}$ & $z_{3}$ & $z_{4}$ \\
\hline$z_{1}$ & - & -0.1860 & 0.8140 & 0.6316 \\
$z_{2}$ & 0.1860 & - & 1 & 0.8176 \\
$z_{3}$ & -0.8140 & -1 & - & -0.1824 \\
$z_{4}$ & -0.6316 & -0.8176 & 0.1824 & - \\
\hline
\end{tabular}

That is to say, the ranking result is insensitive to the $\lambda$ values when using the decision making method combined VIKOR and QUALIFLEX in this case. The sensitivity analysis validated the robustness of the proposed method in a certain degree.

\subsection{Comparison analysis}

Several existing related decision making methods, i.e. aggregation operators (Fang and Ye, 2017), VIKOR and QUALIFLEX, are compared with the combined VIKOR-QUALIFLEX method in this subsection.

Firstly, the linguistic neutrosophic weighted arithmetic averaging (LNWAA) operator and the linguistic neutrosophic weighted geometric averaging (LNWGA) operator are used to get the ranking order through resolving the same problem, respectively. Used the LNWAA operator, the total assessments of CE performance in four enterprises are $T A_{1}^{w a}=\left(s_{3.72}, s_{1.76}, s_{2.26}\right), T A_{2}^{w a}=\left(s_{4.25}, s_{2.22}, s_{1.87}\right)$, $T A_{3}^{w a}=\left(s_{4.33}, s_{2.35}, s_{2.49}\right)$ and $T A_{4}^{w a}=\left(s_{3.87}, s_{2.47}, s_{2.20}\right)$. Because $K\left(T A_{2}^{w a}\right)>K\left(T A_{1}^{w a}\right)>K\left(T A_{3}^{w a}\right)>K\left(T A_{4}^{w a}\right)$, the rank $z_{2}>z_{1}>z_{3}>z_{4}$ is obtained. However, if the LNWGA operator is used, then $T A_{1}^{w g}=\left(s_{3.71}\right.$, $\left.s_{1.74}, s_{2.45}\right), T A_{2}^{w g}=\left(s_{4.37}, s_{2.22}, s_{2.09}\right), T A_{3}^{w g}=\left(s_{4.34}, s_{2.66}, s_{2.91}\right)$ and $T A_{4}^{w g}=\left(s_{3.74}, s_{2.65}, s_{2.49}\right)$. And the ranking order is $z_{2}>z_{1}>z_{4}>z_{3}$ with. $K\left(T A_{2}^{w g}\right)>K\left(T A_{1}^{w g}\right)>K\left(T A_{4}^{w g}\right)>K\left(T A_{3}^{w g}\right)$.

Secondly, only the VIKOR method based on LNN is used to get the rank directly. Since $U_{2}(0.4557)<U_{1}(0.5293)<U_{4}(0.7776)$ $<U_{3}(0.7884) \Rightarrow z_{2}>z_{1}>z_{4}>z_{3} ; \quad$ since $\quad R_{2}(0.0743)<R_{1}(0.0908)$ $<R_{4}(0.1474)<R_{3}(0.1838) \Rightarrow z_{2}>z_{1}>z_{4}>z_{3}$; Furthermore, the compromise values of each option are $C V_{1}=\lambda \frac{U_{1}-U_{j}^{-}}{U_{j}^{+}-U_{j}^{-}}+$ $(1-\lambda) \frac{R_{1}-R_{j}^{-}}{R_{j}^{+}-R_{j}^{-}}=0.1860, \quad C V_{2}=0, \quad C V_{3}=1 \quad$ and $\quad C V_{4}=0.8176$ 
Table 5

The general concordance index of each permutation.

\begin{tabular}{|c|c|c|c|c|c|c|c|c|c|c|c|}
\hline $\mathrm{CI}_{1}$ & $\mathrm{Cl}_{2}$ & $\mathrm{Cl}_{3}$ & $\mathrm{Cl}_{4}$ & $\mathrm{Cl}_{5}$ & $\mathrm{CI}_{6}$ & $\mathrm{Cl}_{7}$ & $\mathrm{Cl}_{8}$ & $\mathrm{Cl}_{9}$ & $C I_{10}$ & $C I_{11}$ & $\mathrm{CI}_{12}$ \\
\hline 2.8948 & 3.2596 & 0.8948 & -0.7404 & 1.6244 & -0.3756 & 3.2668 & 3.6316 & 1.6388 & 0.3756 & 2.3684 & 0.7404 \\
\hline $\mathrm{Cl}_{13}$ & $\mathrm{CI}_{14}$ & $\mathrm{CI}_{15}$ & $\mathrm{Cl}_{16}$ & $\mathrm{Cl}_{17}$ & $\mathrm{CI}_{18}$ & $\mathrm{CI}_{19}$ & $\mathrm{Cl}_{20}$ & $\mathrm{Cl}_{21}$ & $\mathrm{Cl}_{22}$ & $\mathrm{CI}_{23}$ & $\mathrm{CI}_{24}$ \\
\hline-0.7332 & -2.3684 & -0.3612 & -1.6244 & -3.6316 & -3.2596 & 0.3612 & -1.6388 & 0.7332 & -0.8948 & -3.2668 & -2.8948 \\
\hline
\end{tabular}

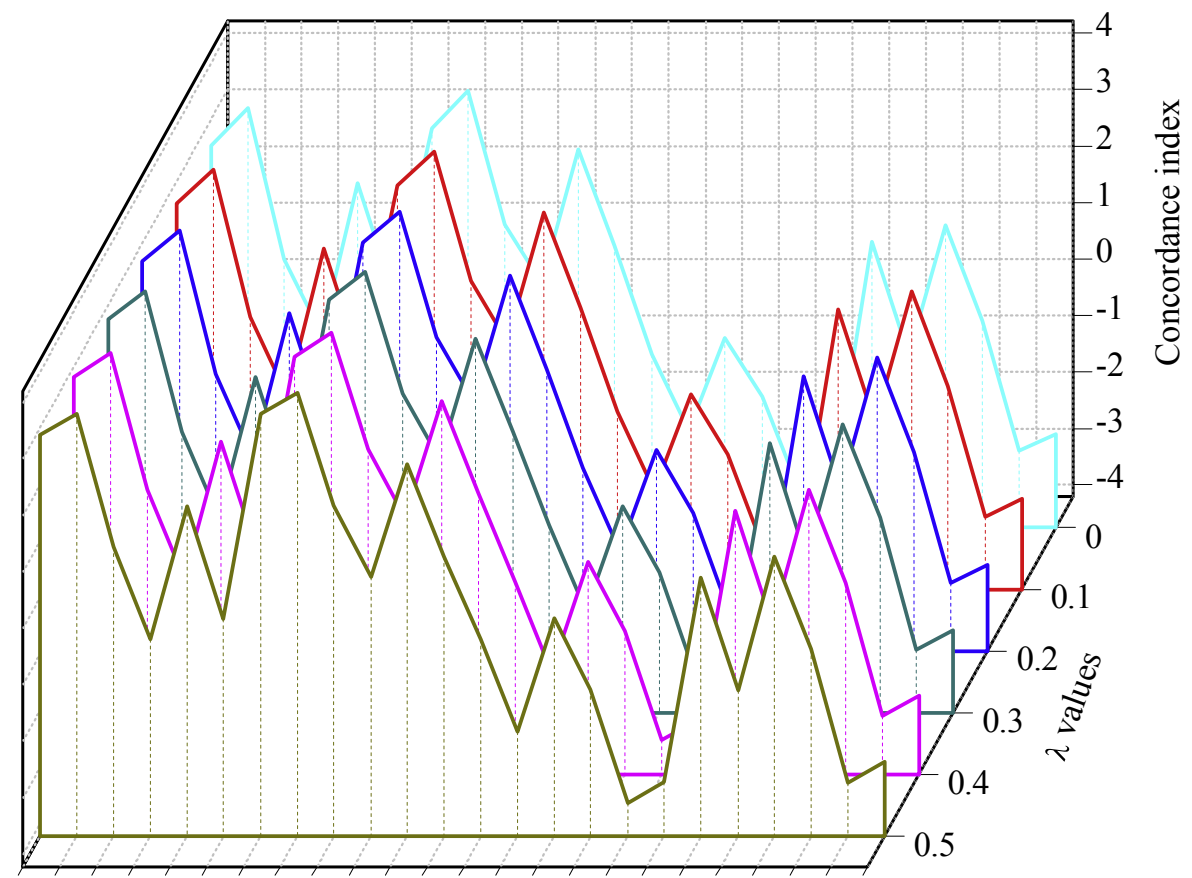

12334567789101112131415161718192021222324

Possible permutations

Fig. 6. Concordance index when $0 \leq \lambda \leq 0.5$

(suppose $\lambda=0.5)$. As $C V_{2}(0)<C V_{1}(0.1860)<C V_{4}(0.8176)$

$<C V_{3}(1)$, the rank is. $z_{2}>z_{1}>z_{4}>z_{3}$.

Finally, only the QUALIFLEX method based on LNN is used to obtain the ranking order. The concordance index is redefined as $C N_{j k}=\sum_{i=1}^{n}\left(K\left(B_{i j}\right)-K\left(B_{i k}\right)\right) \omega_{i}$. Then, the concordance index was calculated as shown in Table 6.

The total concordance index of each permutation can be summarized in Table 7. Since $C N_{7}=0.2396$ is the largest, then the rank is $z_{2}>z_{1}>z_{3}>z_{4}$, and the optimal option is $z_{2}$.

The ranks of different approaches with the same example are shown in Table 8.

From Table 8, it is clear that the difference between various methods is subtle. Among all approaches, the best and second option are always $z_{2}$ and $z_{1}$, respectively. That is to say, only the order of option $z_{3}$ and $z_{4}$ is different in all methods. It demonstrated the availability of the proposed method in some extents. In addition, the reasons for this difference are analyzed as follows:

(1) Same rank order is obtained in both of our approach and method based on LNWGA operator, which is different from the rank of method based on LNWAA operator. It is likely because some original information is distorted in the aggregation process. Then, the rank may be changed with diverse aggregation operators. Hence, methods based on aggregation operators may lack robustness.
(2) The ranking results in VIKOR method and the proposed method are the same. However, the rank only with VIKOR is difficult to get in some cases. Especially when values of the group utility and the individual regret of all options are not the same sequences, some conditions are not met at the same time, then only the compromise solutions are obtained.

(3) QUALIFLEX and our method yield different ranks mainly because of the difference of concordance index defined in two methods. The definition of concordance index in QUALIFLEX only considers the affections of score function between two LNNs. However, the group utility and the individual regret are contained in the presented approach.

Based on the analyses above, the strengths of the proposed method are displayed as follows:

(1) The basic element in decision making matrix is LNN, which has a good characteristic of reserving initial decision making information. All the truth-membership degree, the hesitance-membership degree and the false-membership degree can be described with linguistic variables in a LNN.

(2) The idea of entropy is used as a reference, an algorithm with respect to linguistic neutrosophic environment is constructed to obtain the index weight values.

(3) The VIKOR and QUALIFLEX methods are combined to get the ranking order. On the one hand, the group utility and the 


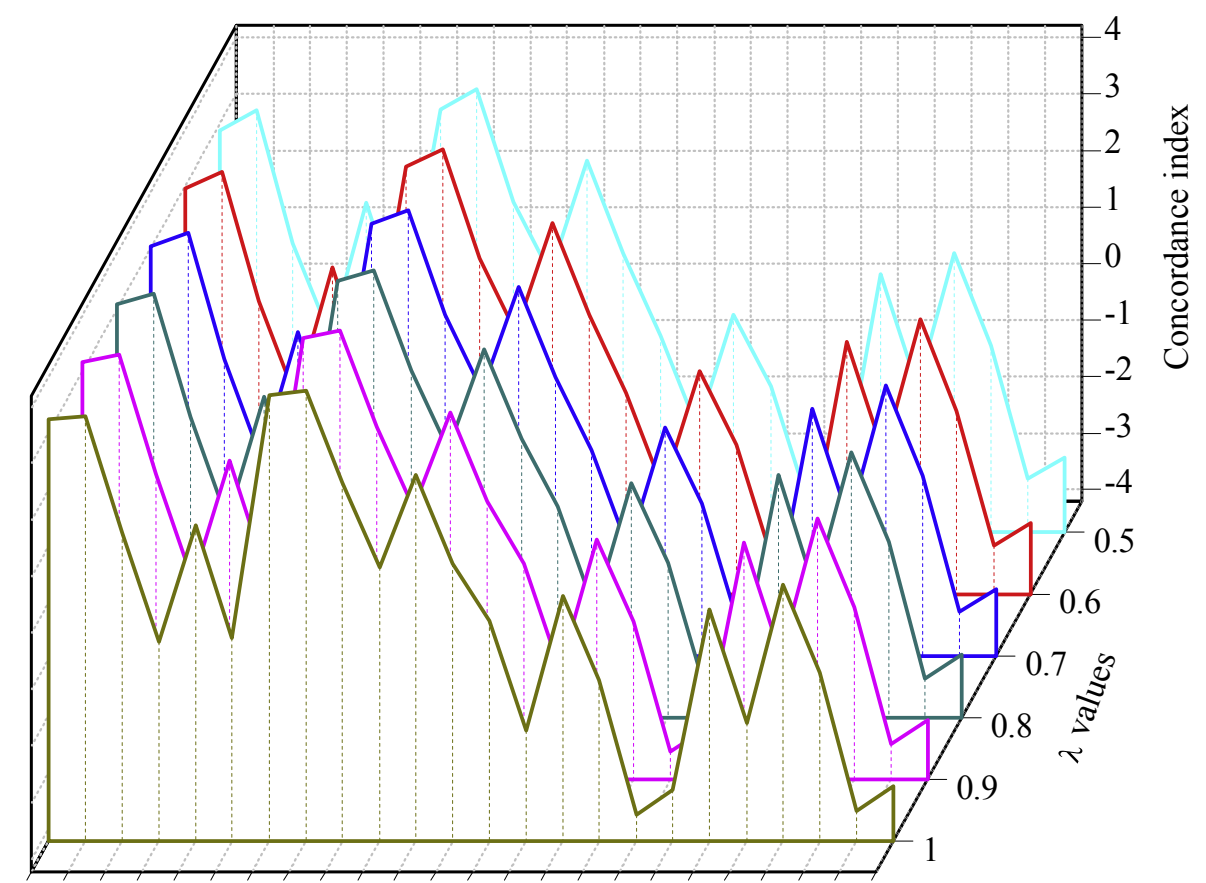

12234567789101112131415161718192021222324

Possible permutations

Fig. 7. Concordance index when $0.5 \leq \lambda \leq 1$

Table 6

The concordance index. $C N_{j k}$

\begin{tabular}{lllll}
\hline$C N_{j k}$ & $z_{1}$ & $z_{2}$ & $z_{3}$ & $z_{4}$ \\
\hline$z_{1}$ & - & -0.0216 & 0.0231 & 0.0437 \\
$z_{2}$ & 0.0216 & - & 0.0653 & 0.0653 \\
$z_{3}$ & -0.0231 & -0.0653 & - & 0.0206 \\
$z_{4}$ & -0.0437 & -0.00653 & -0.0206 & - \\
\hline
\end{tabular}

individual regret are considered simultaneously in the proposed method. The sensitivity analysis proved it has a good robustness. On the other hand, listing all possible permutations is a simple and operative way when many indexes should be taken into account.

\section{Conclusions}

Currently, CE has become a basic national policy in many countries. With the acceleration of the modernization process, developing $\mathrm{CE}$ is effective to resolve the dilemma between economic growth and resource shortages or environmental degradation. This paper focused on finding a reasonable method to evaluate the performance of CE for PCFs. The evaluation index system of CE for PCFs was established with 5 criteria and 14 sub-criteria for convenience of making assessments by experts. LNNs were utilized to express evaluation values so that original information can be retained as much as possible. Then, the VIKOR-QUALIFLEX method was proposed to obtain the ranking results. The reason is two-fold. On the one hand, considering that many indexes should be taken into account, the computation of aggregation operators are large and complex. On the other hand, as an extremely crucial index, the value of general concordance index can directly affect the ranks. For the sake of reasonable results, a concordance index based on VIKOR, which contained the group utility and the individual regret, was defined. Besides, the formula of entropy in line with LNN was afforded so that the index weight values can be calculated. Finally, the developed method was applied to evaluate the performance of

Table 7

The total concordance index of each permutation.

\begin{tabular}{|c|c|c|c|c|c|c|c|c|c|c|c|}
\hline $\mathrm{CN}_{1}$ & $\mathrm{CN}_{2}$ & $\mathrm{CN}_{3}$ & $\mathrm{CN}_{4}$ & $\mathrm{CN}_{5}$ & $\mathrm{CN}_{6}$ & $\mathrm{CN}_{7}$ & $\mathrm{CN}_{8}$ & $\mathrm{CN}_{9}$ & $\mathrm{CN}_{10}$ & $\mathrm{CN}_{11}$ & $\mathrm{CN}_{12}$ \\
\hline 0.1964 & 0.1552 & 0.0658 & -0.0648 & 0.0246 & -0.1060 & 0.2396 & 0.1984 & 1.934 & 0.1060 & 0.1110 & 0.0648 \\
\hline $\mathrm{CN}_{13}$ & $\mathrm{CN}_{14}$ & $\mathrm{CN}_{15}$ & $\mathrm{CN}_{16}$ & $\mathrm{CN}_{17}$ & $\mathrm{CN}_{18}$ & $\mathrm{CN}_{19}$ & $\mathrm{CN}_{20}$ & $\mathrm{CN}_{21}$ & $\mathrm{CN}_{22}$ & $\mathrm{CN}_{23}$ & $\mathrm{CN}_{24}$ \\
\hline 0.0196 & -0.1110 & 0.0628 & -0.0246 & -0.1984 & -0.1552 & -0.0628 & -0.1934 & -0.0196 & -0.0658 & -0.8273 & -0.7841 \\
\hline
\end{tabular}

Table 8

Ranks with various methods.

\begin{tabular}{|c|c|c|c|}
\hline Methods & Ranks & Best company & Worst company \\
\hline Method based on the LNWAA operator (Fang and Ye, 2017) & $z_{2}>z_{1}>z_{3}>z_{4}$ & $z_{2}$ & $z_{4}$ \\
\hline Method based on the LNWGA operator (Fang and Ye, 2017) & $z_{2}>z_{1}>z_{4}>z_{3}$ & $z_{2}$ & $z_{3}$ \\
\hline Method with VIKOR based on LNN & $z_{2}>z_{1}>z_{4}>z_{3}$ & $z_{2}$ & $z_{3}$ \\
\hline Method with QUALIFLEX based on LNN & $z_{2}>z_{1}>z_{3}>z_{4}$ & $z_{2}$ & $z_{4}$ \\
\hline The presented method & $z_{2}>z_{1}>z_{4}>z_{3}$ & $z_{2}$ & $z_{3}$ \\
\hline
\end{tabular}


CE for PCFs in China. The sensitivity analysis demonstrated that the proposed method had strong robustness, and the comparison analysis showed that the evaluation results were effective. Hence, the proposed VIKOR-QUALIFLEX method can be employed to assess the CE for PCFs, which can be utilized to obtain reliable and stable ranking results.

In the future study, a standard evaluation index system for performance evaluation of CE for PCFs can be built based on the prior research and the proposed method. In addition, more decision making methods can be developed to deal with complex decision making problems in PCFs, or the proposed VIKOR-QUALIFLEX method can be applied in other fields.

\section{Acknowledgement}

This work was supported by Fundamental Research Funds of Central South University (No. 2018zzts218), Survey Research Funds of Central South University (No. 2018dcyj052), and National Natural Science Foundation of China (No. 51774321). Besides, We also sincerely thank the anonymous reviewers for their helpful and constructive suggestions and the editors for their careful and patient work.

\section{Appendix}

Table 9

Nomenclatures.

\begin{tabular}{|c|c|}
\hline Terms & Explanations \\
\hline VIKOR & A decision making method based on concordance index to select the optimal option. \\
\hline Concordance index & A index combined group utility and individual regret. \\
\hline QUALIFLEX & A decision making method used to obtain a ranking order through itemizing all possible permutations. \\
\hline Linguistic phrases & Some phrases like "bad", "good", "very good" and so on, which can be denoted as $p_{1}=$ bad, $p_{5}=$ good, $p_{6}=$ very good.and so on. \\
\hline Linguistic term set & $\begin{array}{l}\text { A set of lingusitic phrases, which can be expressed as } P=\left\{p_{b} \mid b=0,1, \ldots, 2 v\right\} \text {. For example, a linguistic term set } P=\left\{p_{0}=\right. \\
\left.\text { very bad, } p_{1}=\text { bad, } p_{2}=\text { slightly bad, } p_{3}=\text { medium, } p_{4}=\text { slightly good, } p_{5}=\text { good, } p_{6}=\text { very good }\right\}\end{array}$ \\
\hline Linguistic neutrosophic number (LNN) & $\begin{array}{l}\text { A number contain three linguistic phrases, which can be denoted as } B=\left(b_{T}, b_{I}, b_{F}\right) \text {. For example, the descriptions of three } \\
\text { linguistic phrases "bad", "good" and "very good" can be replace by a } \operatorname{LNN} B=\left(p_{1}, p_{5}, p_{6}\right) \text {. }\end{array}$ \\
\hline Truth-membership degree & The first linguistic phrase in a LNN. For example, given a LNN $B=\left(p_{1}, p_{5}, p_{6}\right)$, then $p_{1}$ is the truth-membership degree. \\
\hline Indeterminacy-membership degree & $\begin{array}{l}\text { The second linguistic phrase in a LNN. For example, given a LNN } B=\left(p_{1}, p_{5}, p_{6}\right) \text {, then } p_{5} \text { is the indeterminacy-membership } \\
\text { degree. }\end{array}$ \\
\hline Falsity-membership degree & The third linguistic phrase in a LNN. For example, given a LNN $B=\left(p_{1}, p_{5}, p_{6}\right)$, then $p_{6}$ is the falsity-membership degree. \\
\hline Entropy & A value presented by Shannon to measure the amount of information. \\
\hline score function & A function used to compare two fuzzy numbers. \\
\hline Hamming distance & A formula used to measure the distance/difference between two values. \\
\hline
\end{tabular}

Table 10

The initial assessment matrixH.

\begin{tabular}{|c|c|c|c|c|}
\hline$H$ & $z_{1}$ & $z_{2}$ & $z_{3}$ & $z_{4}$ \\
\hline$c_{1}$ & $\left(p_{2}, p_{3}, p_{6}\right)$ & $\left(p_{1}, p_{2}, p_{4}\right)$ & $\left(p_{1}, p_{5}, p_{5}\right)$ & $\left(p_{2}, p_{4}, p_{2}\right)$ \\
\hline$c_{2}$ & $\left(p_{3}, p_{4}, p_{3}\right)$ & $\left(p_{1}, p_{5}, p_{5}\right)$ & $\left(p_{2}, p_{5}, p_{3}\right)$ & $\left(p_{1}, p_{3}, p_{5}\right)$ \\
\hline$c_{3}$ & $\left(p_{4}, p_{3}, p_{5}\right)$ & $\left(p_{2}, p_{3}, p_{5}\right)$ & $\left(p_{3}, p_{3}, p_{4}\right)$ & $\left(p_{1}, p_{2}, p_{3}\right)$ \\
\hline$c_{4}$ & $\left(p_{2}, p_{5}, p_{5}\right)$ & $\left(p_{2}, p_{4}, p_{5}\right)$ & $\left(p_{1}, p_{4}, p_{2}\right)$ & $\left(p_{3}, p_{5}, p_{4}\right)$ \\
\hline$c_{5}$ & $\left(p_{5}, p_{3}, p_{2}\right)$ & $\left(p_{4}, p_{3}, p_{4}\right)$ & $\left(p_{3}, p_{5}, p_{2}\right)$ & $\left(p_{2}, p_{4}, p_{1}\right)$ \\
\hline$c_{6}$ & $\left(p_{5}, p_{1}, p_{4}\right)$ & $\left(p_{3}, p_{2}, p_{4}\right)$ & $\left(p_{4}, p_{4}, p_{3}\right)$ & $\left(p_{4}, p_{1}, p_{1}\right)$ \\
\hline$c_{7}$ & $\left(p_{3}, p_{1}, p_{2}\right)$ & $\left(p_{5}, p_{1}, p_{2}\right)$ & $\left(p_{5}, p_{3}, p_{5}\right)$ & $\left(p_{3}, p_{3}, p_{2}\right)$ \\
\hline$c_{8}$ & $\left(p_{3}, p_{1}, p_{3}\right)$ & $\left(p_{5}, p_{2}, p_{1}\right)$ & $\left(p_{5}, p_{3}, p_{2}\right)$ & $\left(p_{4}, p_{2}, p_{4}\right)$ \\
\hline$c_{9}$ & $\left(p_{2}, p_{4}, p_{3}\right)$ & $\left(p_{2}, p_{4}, p_{2}\right)$ & $\left(p_{2}, p_{3}, p_{1}\right)$ & $\left(p_{2}, p_{3}, p_{3}\right)$ \\
\hline$c_{10}$ & $\left(p_{3}, p_{5}, p_{4}\right)$ & $\left(p_{2}, p_{3}, p_{5}\right)$ & $\left(p_{1}, p_{5}, p_{5}\right)$ & $\left(p_{1}, p_{2}, p_{2}\right)$ \\
\hline$c_{11}$ & $\left(p_{1}, p_{5}, p_{4}\right)$ & $\left(p_{2}, p_{4}, p_{4}\right)$ & $\left(p_{1}, p_{5}, p_{4}\right)$ & $\left(p_{3}, p_{4}, p_{2}\right)$ \\
\hline$c_{12}$ & $\left(p_{4}, p_{2}, p_{5}\right)$ & $\left(p_{5}, p_{1}, p_{1}\right)$ & $\left(p_{3}, p_{4}, p_{4}\right)$ & $\left(p_{2}, p_{4}, p_{1}\right)$ \\
\hline$c_{13}$ & $\left(p_{3}, p_{2}, p_{1}\right)$ & $\left(p_{4}, p_{3}, p_{2}\right)$ & $\left(p_{5}, p_{2}, p_{1}\right)$ & $\left(p_{5}, p_{1}, p_{1}\right)$ \\
\hline$c_{14}$ & $\left(p_{4}, p_{3}, p_{1}\right)$ & $\left(p_{2}, p_{2}, p_{1}\right)$ & $\left(p_{4}, p_{1}, p_{3}\right)$ & $\left(p_{4}, p_{3}, p_{2}\right)$ \\
\hline
\end{tabular}

Table 11

The values of score function $K\left(B_{i j}\right)$.

\begin{tabular}{|c|c|c|c|c|}
\hline & $z_{1}$ & $z_{2}$ & $z_{3}$ & $z_{4}$ \\
\hline$c_{1}$ & 0.6111 & 0.6111 & 0.8333 & 0.5556 \\
\hline$c_{2}$ & 0.5556 & 0.8333 & 0.6667 & 0.7222 \\
\hline$c_{3}$ & 0.5556 & 0.6667 & 0.5556 & 0.5556 \\
\hline$c_{4}$ & 0.7778 & 0.7222 & 0.6111 & 0.6667 \\
\hline$c_{5}$ & 0.6667 & 0.5000 & 0.4444 & 0.5000 \\
\hline$c_{6}$ & 0.6667 & 0.5000 & 0.5000 & 0.7778 \\
\hline$c_{7}$ & 0.6667 & 0.7778 & 0.5000 & 0.5556 \\
\hline$c_{8}$ & 0.6111 & 0.7778 & 0.6667 & 0.5556 \\
\hline$c_{9}$ & 0.6111 & 0.5556 & 0.4444 & 0.5556 \\
\hline$c_{10}$ & 0.6667 & 0.6667 & 0.8333 & 0.5000 \\
\hline$c_{11}$ & 0.7778 & 0.6667 & 0.7778 & 0.5000 \\
\hline$c_{12}$ & 0.5000 & 0.8333 & 0.3889 & 0.5000 \\
\hline$c_{13}$ & 0.6667 & 0.6111 & 0.7778 & 0.8333 \\
\hline$c_{14}$ & 0.6667 & 0.6111 & 0.6667 & 0.6111 \\
\hline
\end{tabular}


Table 12

The positive ideal solution and the negative ideal solution.

\begin{tabular}{|c|c|c|c|c|c|c|c|}
\hline & $c_{1}$ & $c_{2}$ & $c_{3}$ & $c_{4}$ & $c_{5}$ & $c_{6}$ & $c_{7}$ \\
\hline$B_{i}^{+}$ & $\left(p_{5}, p_{1}, p_{1}\right)$ & $\left(p_{5}, p_{1}, p_{1}\right)$ & $\left(p_{4}, p_{3}, p_{1}\right)$ & $\left(p_{4}, p_{1}, p_{1}\right)$ & $\left(p_{5}, p_{3}, p_{2}\right)$ & $\left(p_{4}, p_{1}, p_{1}\right)$ & $\left(p_{5}, p_{1}, p_{2}\right)$ \\
\hline \multirow[t]{2}{*}{$B_{i}^{-}$} & $\left(p_{4}, p_{2}, p_{4}\right)$ & $\left(p_{3}, p_{2}, p_{3}\right)$ & $\left(p_{2}, p_{3}, p_{1}\right)$ & $\left(p_{5}, p_{2}, p_{4}\right)$ & $\left(p_{3}, p_{5}, p_{2}\right)$ & $\left(p_{3}, p_{2}, p_{4}\right)$ & $\left(p_{5}, p_{3}, p_{5}\right)$ \\
\hline & $c_{8}$ & $c_{9}$ & $c_{10}$ & $c_{11}$ & $c_{12}$ & $c_{13}$ & $c_{14}$ \\
\hline$B_{i}^{+}$ & $\left(p_{5}, p_{2}, p_{1}\right)$ & $\left(p_{4}, p_{2}, p_{3}\right)$ & $\left(p_{5}, p_{1}, p_{1}\right)$ & $\left(p_{5}, p_{1}, p_{2}\right)$ & $\left(p_{5}, p_{1}, p_{1}\right)$ & $\left(p_{5}, p_{1}, p_{1}\right)$ & $\left(p_{4}, p_{3}, p_{1}\right)$ \\
\hline$B_{i}^{-}$ & $\left(p_{4}, p_{2}, p_{4}\right)$ & $\left(p_{4}, p_{3}, p_{5}\right)$ & $\left(p_{5}, p_{4}, p_{4}\right)$ & $\left(p_{3}, p_{2}, p_{4}\right)$ & $\left(p_{3}, p_{4}, p_{4}\right)$ & $\left(p_{4}, p_{3}, p_{2}\right)$ & $\left(p_{2}, p_{2}, p_{1}\right)$ \\
\hline
\end{tabular}

Table 13

Hamming distanced $\left(B_{i j}, B_{i}^{+}\right)$.

\begin{tabular}{llllllll}
\hline & $c_{1}$ & $c_{2}$ & $c_{3}$ & $c_{4}$ & $c_{5}$ & $c_{6}$ & $c_{7}$ \\
\hline$d\left(B_{i 1}, B_{i}^{+}\right)$ & 0.2222 & 0.2778 & 0.1111 & 0 & 0 & 0.2222 & 0.1111 \\
$d\left(B_{i 2}, B_{i}^{+}\right)$ & 0.2222 & 0 & 0 & 0.0556 & 0.1667 & 0.2778 & 0 \\
$d\left(B_{i 3}, B_{i}^{+}\right)$ & 0 & 0.1667 & 0.1111 & 0.2778 & 0.2222 & 0.2778 & 0.2778 \\
$d\left(B_{i 4}, B_{i}^{+}\right)$ & 0.2778 & 0.1111 & 0.2222 & 0.1111 & 0.2778 & 0 & 0.2222 \\
\hline & $c_{8}$ & $c_{9}$ & $c_{10}$ & $c_{11}$ & $c_{12}$ & $c_{13}$ & $c_{14}$ \\
\hline$d\left(B_{i 1}, B_{i}^{+}\right)$ & 0.2778 & 0 & 0.1667 & 0 & 0.3333 & 0.1667 & 0 \\
$d\left(B_{i 2}, B_{i}^{+}\right)$ & 0 & 0.0556 & 0.1667 & 0.1111 & 0 & 0.2222 & 0.1667 \\
$d\left(B_{i 3}, B_{i}^{+}\right)$ & 0.1111 & 0.1667 & 0 & 0 & 0.4444 & 0.0556 & 0.2222 \\
$d\left(B_{i 4}, B_{i}^{+}\right)$ & 0.2222 & 0.0556 & 0.3333 & 0.2778 & 0.3333 & 0 & 0.0556 \\
\hline
\end{tabular}

\section{References}

Adler, N., Yazhemsky, E., Tarverdyan, R., 2010. A framework to measure the relative socio-economic performance of developing countries. Soc. Econ. Plann. Sci. 44 (2), 73-88.

Ali, S.H., Giurco, D., Arndt, N., Nickless, E., Brown, G., Demetriades, A., Durrheim, R., Enriquez, M.A., Kinnaird, J., Littleboy, A., Meinert, L.D., Oberhänsli, R., Salem, J. Schodde, R., Schneider, G., Vidal, O., Yakovleva, N., 2017. Mineral supply for sustainable development requires resource governance. Nature 543 (7645) $367-372$.

Azapagic, A., 2004. Developing a framework for sustainable development indicators for the mining and minerals industry. J. Clean. Prod. 12 (6), 639-662.

Boulding, K.E., 1966. The economics of the coming spaceship earth. In: Jarrett, $H$. (Ed.), Environmental Quality Issues in a Growing Economy. Johns Hopkins University Press, Baltimore, MD.

Brunner, P.H., 2010. Substance flow analysis as a decision support tool for phosphorus management. J. Ind. Ecol. 14 (6), 870-873.

Calas, G., 2017. Mineral resources and sustainable development. Elements 13 (5), $301-306$.

Chen, T.Y., Chang, C.H., Lu, J.R., 2013. The extended QUALIFLEX method for multiple criteria decision analysis based on interval type-2 fuzzy sets and applications to medical decision making. Eur. J. Oper. Res. 226 (3), 615-625.

Chen, Q., Zhang, Q., Fourie, A., Xin, C., 2017a. Utilization of phosphogypsum and phosphate tailings for cemented paste backfill. J. Environ. Manag. 201, 19-27.

Chen, W., Zhong, S.Z., Geng, Y., Chen, Y.H., Cui, X.W., Wu, Q., Pan, H.Y., Wu, R., Sun, L. Tian, X., 2017b. Emergy based sustainability evaluation for Yunnan Province, China. J. Clean. Prod. 162, 1388-1397.

Commoner, B., 1971. The Closing Circle: Nature. Man and Technology, Random House, New York.

Cooper, J., Lombardi, R., Boardman, D., Carliell-Marquet, C., 2011. The future distribution and production of global phosphate rock reserves. Resour. Conserv. Recycl. 57, 78-86.

Cordell, D., Neset, T.S., 2014. Phosphorus vulnerability: a qualitative framework for assessing the vulnerability of national and regional food systems to the multidimensional stressors of phosphorus scarcity. Global Environ. Change 24 $108-122$.

Cordell, D., White, S., 2014. Life's bottleneck: sustaining the world's phosphorus for a food secure future. Annu. Rev, Environ. Resour. 39, 161-188.

Cordell, D., Rosemarin, A., Schröder, J.J., Smit, A.L., 2011. Towards global phosphorus security: a systems framework for phosphorus recovery and reuse options. Chemosphere 84 (6), 747-758.

Elloumi, N., Belhaj, D., Mseddi, S., Zouari, M., Abdallah, F.B., Woodward, S., Kallel, M. 2017. Response of Nerium oleander to phosphogypsum amendment and its potential use for phytoremediation. Ecol. Eng. 99, 164-171.

European Commission, 2011. Roadmap to a Resource Efficient Europe. COM, p. 571 final).

Fang, Z., Ye, J., 2017. Multiple attribute group decision-making method based on linguistic neutrosophic numbers. Symmetry 9 (7). https://doi.org/10.3390/ sym9070111.

Guo, B., Geng, Y., Ren, J.Z., Zhu, L., Liu, Y.X., Sterr, T., 2017. Comparative assessment of circular economy development in China's four megacities: the case of Beijing, Chongqing, Shanghai and Urumqi. J. Clean. Prod. 162, 234-246.

Hatayama, H., Tahara, K., Daigo, I., 2015. Worth of metal gleaning in mining and recycling for mineral conservation. Miner. Eng. 76, 58-64.

Hosseini, H.M., Kaneko, S., 2011. Dynamic sustainability assessment of countries at the macro level: a principal component analysis. Ecol. Indicat. 11 (3), 811-823.

Hou, Y., Wang, X., Zhan, J., Li, C.F., Tian, S.L., Gao, H.P., 2012. Technical progress of purification and comprehensive utilization of yellow phosphorus tail gas. J. Kunming Univ. Sci. Technol. (Sci. Technol.) 37 (1), 73-77.

Ji, P., Zhang, H.Y., Wang, J.Q., 2017. Fuzzy decision-making framework for treatment selection based on the combined QUALIFLEX-TODIM method. Int. J. Syst. Sci. 3072-3086.

Jia, Z.W., 2012. Study on the Development of Phosphorus Chemical Industry in china from the Perspective of Circular Economy, a Case Study in Wengfu Group (Master thesis, Guiyang).

Khishtandar, S., Zandieh, M., Dorri, B., 2017. A multi criteria decision making framework for sustainability assessment of bioenergy production technologies with hesitant fuzzy linguistic term sets: the case of Iran. Renew. Sustain. Energy Rev. 77, 1130-1145.

Kirchherr, J., Reike, D., Hekkert, M., 2017. Conceptualizing the circular economy: an analysis of 114 definitions. Resour. Conserv. Recycl. 127, 221-232.

Kodera, H., Hatamoto, M., Abe, K., Kindaichi, T., Ozaki, N., Ohashi, A., 2013. Phosphate recovery as concentrated solution from treated wastewater by a PAOenriched biofilm reactor. Water Res. 47 (6), 2025-2032.

Korhonen, J., Honkasalo, A., Seppälä, J., 2018. Circular economy: the concept and its limitations. Ecol. Econ. 143, 37-46.

Laurence, D., 2011. Establishing a sustainable mining operation: an overview. J. Clean. Prod. 19 (2), 278-284.

Lèbre, É., Corder, G.D., Golev, A., 2017. Sustainable practices in the management of mining waste: a focus on the mineral resource. Miner. Eng. 107, 34-42.

Li, Y.Q., Jia, R.Q., 2006. Application of cyclic economy in mining industry. Express Inform. Min. Ind 11, 5-8.

Li, N., Zhao, H., 2016. Performance evaluation of eco-industrial thermal power plants by using fuzzy GRA-VIKOR and combination weighting techniques. J. Clean. Prod. 135, 169-183.

Li, X.B., Zhou, Z.L., Zhao, G.Y., Liu, Z.X., 2008a. Utilization of phosphogypsum for backfilling, way to relieve its environmental impact. Gospod. Surowcami Miner. $24(4 / 3), 226-232$.

Li, Z.X., Ming, D.Z., Zhong, Y., 2008b. Comprehensive utilization of fluorine resource associated with phosphate rock. Ph. Comp. Fert 23 (1), 64-66.

Li, H., Bao, W., Xiu, C., Zhang, Y., Xu, H., 2010. Energy conservation and circular economy in China's process industries. Energy 35 (11), 4273-4281.

Liang, W.Z., Zhao, G.Y., Wu, H., 2017. Evaluating investment risks of metallic mines using an extended TOPSIS method with linguistic neutrosophic numbers. Symmetry 9 (8). https://doi.org/10.3390/sym9080149.

Liang, W.Z., Zhao, G.Y., Hong, C.S., 2018. Selecting the optimal mining method with extended multi-objective optimization by ratio analysis plus the full multiplicative form (MULTIMOORA) approach. Neural Comput. Appl. https://doi.org/ 10.1007/s00521-018-3405-5.

Liao, H.C., Jiang, L.S., Xu, Z.S., Xu, J.P., Herrera, F. 2017. A linear programming method for multiple criteria decision making with probabilistic linguistic information. Inf. Sci. 415, 341-355.

Liu, H.C., You, J.X., Li, P., Su, Q., 2016. Failure mode and effect analysis under uncertainty: an integrated multiple criteria decision making approach. IEEE Trans. Reliab. 65 (3), 1380-1392.

Luo, S.Z., Cheng, P.F., Wang, J.Q., Huang, Y.J., 2017. Selecting project delivery systems based on simplified neutrosophic linguistic preference relations. Symmetry 9 (8). https://doi.org/10.3390/sym9080151.

Ma, S.J., Hu, S., Chen, D., Zhu, B., 2015. A case study of a phosphorus chemical firm's application of resource efficiency and eco-efficiency in industrial metabolism under circular economy. J. Clean. Prod. 87, 839-849.

Meadows, D.H., Meadows, D.L., Randers, J., Behrens, W.W., 1972. The Limits to Growth. Universe Books, New York.

National Bureau of Statistics of the People 's Republic of China (NBSPRC), 2016. China Statistical Yearbook. China Statistics Press, Beijing, 2007, 2008, 2009, 2010, 2011, 2012, 2013, 2014, 2015, 2016.

Nesme, T., Withers, P.J., 2016. Sustainable strategies towards a phosphorus circular 
economy. J. Clean. Prod. 104 (3), 259-264.

Opricovic, S., Tzeng, G.H., 2004. Compromise solution by MCDM methods: a comparative analysis of VIKOR and TOPSIS. Eur. J. Oper. Res. 156 (2), 445-455. Pan, H.Y., Zhang, X.H., Wang, Y.Q., Qi, Y., Wu, J., Lin, L.L., Peng, H., Qi, H., Yu, X.Y., Zhang, Y.Z., 2016. Emergy evaluation of an industrial park in Sichuan Province, China: a modified emergy approach and its application. J. Clean. Prod. 135, 105-118.

Pearce, D.W., Turner, R.K., 1990. Economics of Natural Resources and the Environment. Harvester Wheatsheaf, Hertfordshire.

Rostamzadeh, R., Govindan, K., Esmaeili, A., Sabaghi, M., 2015. Application of fuzzy VIKOR for evaluation of green supply chain management practices. Ecol. Indicat. 49, 188-203.

Shannon, C.E., 1948. A mathematical theory of communication. Bell Syst. Tech. J 27 (3), 379-423.

Shmelev, S.E., Rodríguez-Labajos, B., 2009. Dynamic multidimensional assessment of sustainability at the macro level: the case of Austria. Ecol. Econ. 68 (10), 2560-2573.

Smit, A.L., Bindraban, P.S., Schröder, J.J., Conijn, J.G., Van der Meer, H.G., 2009. Phosphorus in Agriculture: Global Resources, Trends and Developments. Plant Research International B.V, Wageningen, The Netherlands.

Spangenberg, J.H., Pfahl, S., Deller, K., 2002. Towards indicators for institutional sustainability: lessons from an analysis of Agenda 21. Ecol. Indicat. 2 (1), 61-77.

The State Department, 2016. National Mineral Resource Planning (2016-2020). http://www.mlr.gov.cn/zwgk/ghjh/201612/t20161205_1423357.htm.

Tran, A.T.K., Zhang, Y., Corte, D.D., Hannes, J.B., Ye, W.Y., Mondal, P., Jullok, N., Meesschaert, B., Pinoy, L., Van der Bruggen, B., 2014. P-recovery as calcium phosphate from wastewater using an integrated selectrodialysis/crystallization process. J. Clean. Prod. 77, 140-151.

Tsai, W.T., 2010. Energy sustainability from analysis of sustainable development indicators: a case study in Taiwan. Renew. Sustain. Energy Rev. 14 (7), 2131-2138.

Valenzuela-Venegas, G., Salgado, J.C., Díaz-Alvarado, F.A., 2016. Sustainability indicators for the assessment of eco-industrial parks: classification and criteria for selection. J. Clean. Prod. 133, 99-116.

Van Kauwenbergh, S.J., Stewart, M., Mikkelsen, R., 2013. World reserves of phosphate rock-a dynamic and unfolding story. Better Crops 97, 18-20.

Wang, L., Wang, Y., Sangaiah, A.K., Liao, B., 2017a. Intuitionistic linguistic group decision-making methods based on generalized compensative weighted averaging aggregation operators. Soft Comput 1-13. https://doi.org/10.1007/ s00500-017-2734-0.

Wang, K.Q., Liu, H.C., Liu, L., Huang, J., 2017b. Green supplier evaluation and selection using cloud model theory and the QUALIFLEX method. Sustainability 9 (5), 688. https://doi.org/10.3390/su9050688.

Wang, B., 2014. Research on the Evaluation of Green Mining in China (Doctoral dissertation, Beijing).

Wood, B.J., Von Blanckenburg, F., Ross, N.L., Rosso, J.J., 2017. Mineral resources and the limits to growth. Elements 13 (5), 291-292.

Wu, M.Q., An, Y.L., Zhou, X.D., Xiao, Y., 2009. Establishment of the index system of cleaner production assessment of phosplate mines- - phosplate mines of Guiyang a case study. Environ. Sci. Manage 34 (2), 189-194.

$\mathrm{Xu}$, Z.S., 2005. Deviation measures of linguistic preference relations in group decision making. Omega 33 (3), 249-254.

You, X.Y., You, J.X., Liu, H.C., Zhen, L., 2015. Group multi-criteria supplier selection using an extended VIKOR method with interval 2-tuple linguistic information. Expert Syst. Appl. 42 (4), 1906-1916.

Zhang, X., 2016. Multicriteria pythagorean fuzzy decision analysis: a hierarchical QUALIFLEX approach with the closeness index-based ranking methods. Inf. Sci. 330, 104-124.

Zhang, Z., 2017. Multi-criteria decision-making using interval-valued hesitant fuzzy QUALIFLEX methods based on a likelihood-based comparison approach. Neural Comput. Appl. 28 (7), 1835-1854.

Zhao, J.S., You, X.Y., Liu, H.C., Wu, S.M., 2017a. An extended VIKOR method using intuitionistic fuzzy sets and combination weights for supplier selection. Symmetry 9 (9). https://doi.org/10.3390/sym9090169.

Zhao, H., Zhao, H., Guo, S., 2017b. Evaluating the comprehensive benefit of ecoindustrial parks by employing multi-criteria decision making approach for circular economy. J. Clean. Prod. 142, 2262-2276.

Zhou, J., Gao, H., Shu, Z., Wang, Y., Yan, C., 2012. Utilization of waste phosphogypsum to prepare non-fired bricks by a novel Hydration-Recrystallization process. Construct. Build. Mater. 34, 114-119.

Zhou, Z., Chen, X., Xiao, X., 2013. On evaluation model of circular economy for iron and steel enterprise based on support vector machines with heuristic algorithm for tuning hyper-parameters. Appl. Math. Inform. Sci 7 (6), 2215-2223. 